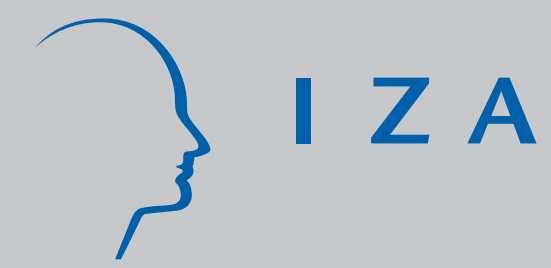

IZA DP No. 8193

Do Interventions Targeted at Micro-Entrepreneurs and Small and Medium-Sized Firms Create Jobs?

A Systematic Review of the Evidence for Low and Middle Income Countries

Michael Grimm

Anna Luisa Paffhausen

May 2014 


\title{
Do Interventions Targeted at Micro-Entrepreneurs and Small and Medium-Sized Firms Create Jobs? A Systematic Review of the Evidence for Low and Middle Income Countries
}

\author{
Michael Grimm \\ University of Passau, \\ Erasmus University Rotterdam and IZA \\ Anna Luisa Paffhausen \\ University of Passau
}

Discussion Paper No. 8193

May 2014

IZA

P.O. Box 7240

53072 Bonn

Germany

Phone: +49-228-3894-0

Fax: +49-228-3894-180

E-mail: iza@iza.org

\begin{abstract}
Any opinions expressed here are those of the author(s) and not those of IZA. Research published in this series may include views on policy, but the institute itself takes no institutional policy positions. The IZA research network is committed to the IZA Guiding Principles of Research Integrity.

The Institute for the Study of Labor (IZA) in Bonn is a local and virtual international research center and a place of communication between science, politics and business. IZA is an independent nonprofit organization supported by Deutsche Post Foundation. The center is associated with the University of Bonn and offers a stimulating research environment through its international network, workshops and conferences, data service, project support, research visits and doctoral program. IZA engages in (i) original and internationally competitive research in all fields of labor economics, (ii) development of policy concepts, and (iii) dissemination of research results and concepts to the interested public.
\end{abstract}

IZA Discussion Papers often represent preliminary work and are circulated to encourage discussion. Citation of such a paper should account for its provisional character. A revised version may be available directly from the author. 


\title{
ABSTRACT
}

\section{Do Interventions Targeted at Micro-Entrepreneurs and Small and Medium-Sized Firms Create Jobs? A Systematic Review of the Evidence for Low and Middle Income Countries}

\begin{abstract}
Worldwide 600 million jobs are needed over the next 15 years to keep employment rates at their current level. Governments, non-governmental organizations and donors spend on targeted programs and broader policies to enhance employment creation and the creation of new firms. Because most employment in low and middle income countries is in micro, small and medium-sized enterprises, these firms are especially targeted by such interventions. Despite these efforts, not much is known about which of these interventions are really effective and under which conditions particular interventions work. This systematic review synthesizes the existing evidence on the impact of these programs. Overall the review shows that creating employment is a very complex challenge. Many conditions have to be met before interventions in favor of individual enterprises do not only improve business practices and performance but also lead to additional jobs. A striking finding is that the study design matters for the impacts found; randomized controlled trials find systematically smaller effects than quasi-experimental studies. A significant shortcoming of the literature is that almost nothing is known about long term effects and cost effectiveness.
\end{abstract}

JEL Classification: D22, G21, J21, O10

Keywords: employment, active labor market policy, firm creation, micro, small and medium sized firms, impact evaluations, systematic review

Corresponding author:

Michael Grimm

University of Passau

Innstrasse 29

94032 Passau

Germany

E-mail: michael.grimm@uni-passau.de

\footnotetext{
* Financial support from the KfW - Development Bank is gratefully acknowledged. We thank in particular Eva Terberger, Christian Schönhofen, Martin Dorschel, Jochen Kluve, Peter Knorringa and Ruerd Ruben for valuable suggestions and comments. Moreover, we thank participants at the WIDER conference on 'Inclusive Growth in Africa' held in September 2013 in Helsinki, at the IZA/World Bank Conference on 'Employment and Development' held in August 2013 in Bonn and at special seminars at the Operations Evaluation Department of the Dutch Ministry of Foreign Affairs and the German Federal Ministry of Economic Cooperation and Development for helpful comments. Excellent research assistance has been provided by Stephan Höller, Erwin Winkler, Georg Seidl and Hendrik Kampert.
} 


\section{Introduction}

Creating new jobs and in particular 'good jobs', i.e. jobs in high productivity sectors and offering decent working conditions, is one of the major challenges most low and middle income countries face. According to the 2013 World Development Report on jobs, worldwide 600 million jobs are needed over the next 15 years to keep employment rates at their current level (World Bank, 2012). Governments, non-governmental organizations and donors spend large amounts of money for targeted programs and broader policies to enhance employment creation and the creation of new firms. Because most employment in low- and middle income countries is in micro, small and medium-sized enterprises (MSMEs) (see e.g. Ayyagari et al., 2011), these firms are often targeted by such interventions. Typical interventions include the provision of finance and financial services, entrepreneurship training, business support services, wage subsidies and measures that transform the business environment for these firms. Despite these efforts, not much is known about which of these interventions are really effective, or, more importantly, under which conditions particular interventions work.

With the trend to conduct rigorous impact evaluations of development interventions, many researchers have started to look more closely at programs and policies that are targeted at MSMEs. This systematic review synthesizes the existing evidence on the impact of these programs and extracts the main lessons. The review reveals several factors and design features likely to increase the probability of interventions aimed at enhancing employment being successful. However, the review also still reveals important knowledge gaps. This stands in sharp contrast to the high number of programs and projects that claim to know how to create jobs and on which considerable funds are being spent. We focus on the following five policy areas: (i) access to finance, (ii) entrepreneurship training, (iii) business development services, (iv) wage subsidies, and (v) improvements to the business environment (e.g. registration procedures). There are many other interventions and policies that may have employment effects such as improvements in energy supply, road construction or trade and exchange rate policies, but given that such policies are typically not targeted it is hard to find a counterfactual and to establish causal evidence. Therefore such interventions and policies are not considered in this review. Our work builds on a few earlier reviews which however have not focused specifically on employment creation in MSMEs in developing countries or considered only a sub-set of the policies we focus on.

McKenzie and Woodruff (2014) review the quality and findings from business training and entrepreneurship evaluations. They focus in particular on statistical power, measurement issues and attrition. Across the reviewed studies, they find only modest impacts on survivorship but stronger impacts on business creation. Bruhn and McKenzie (2013) review the rigorous evidence on entry regulation and formalization of microenterprises. They conclude that formalizing firms is generally difficult and the effects of formalization on firms are in most cases very modest if not insignificant. In an earlier publication McKenzie (2010) reviews a few finance evaluations (all pre-2009) in which the results not only raise questions about the appropriateness of many existing micro-finance programs but also where the pure quantity of studies also suggests that many more impact evaluations need to be conducted to close the relevant knowledge gaps. Tripney et al. (2013) conducted a systematic review of post-basic technical and vocational education and training (TVET) interventions to improve employability and employment of TVET graduates in Low and Middle Income Countries (LMICS). While the authors are concerned with the same outcome as this systematic review, they do not explicitly focus on employment creation in MSMEs. This applies also to Stewart et al. (2012) who assessed whether different financial instruments effectively enable poor people, and especially women, to engage in meaningful economic opportunities in LMICs, Vaessen et al. (2012) who are currently assessing the effect of microcredit on women's control over household spending, Hagen-Zanker et al. (2011) who focused on the impact of employment guarantee schemes and cash transfers on the poor, Duvendack et al. (2011) who analyzed the evidence on the impact of microfinance on the well-being of the poor, Betcherman (2014) who reviews studies that explore the effects of labor market regulations on employment and other outcomes as well as Stewart et al. (2010) who assessed the impact of microfinance on poor households in Sub-Saharan Africa. 
Other reviews focus on policy areas we do not cover, for the reasons given above. These include Cirera et al. (2011) who synthesized the evidence of the impact of tariff reductions on employment and fiscal revenue, Cirera et al. (2013) who focused on the impact of free trade zones on employment and wages and Nataraj et al. (2012) who assessed the impact of labor market regulations on employment in low income countries. Other authors focused on youth employment, but again, do not consider MSMEs specifically (Betcherman et al., 2007; Puerto, 2007).

A meta-analysis on entrepreneurship programs in developing countries conducted by Cho and Honorati (2014) is so far the most relevant synthesis of evidence with respect to the purpose of this review. The authors considered a sub-set of the studies we review in the area of finance and training. They focus on a whole range of business outcomes and find that finance and training interventions to promote MSME development are more effective in changing intermediate outcomes, like business knowledge and practice, than increasing a general set of labor market activities. For the latter, the combination of training and finance proves to be the most effective though this depends also on the type of beneficiary that is being targeted. This review will substantially add to the work done by Cho and Honorati (2014), first, by updating and broadening the evidence base considerably, taking into account also policy areas other than finance and training and, second, by choosing a strong focus on employment and business creation.

The remainder of this review is organized as follows. In Section 2 we lay out our inclusion criteria and the search strategy. In Section 3 we propose a theory of change which will guide our analysis along the causal chain, linking program inputs and employment outcomes. In Sections 4 and 5 we present our search results and a narrative synthesis of the evidence. The results from a meta-regression analysis are presented and discussed in Section 6. In Section 7 we conclude.

\section{Inclusion criteria and search strategy}

\subsection{Inclusion criteria}

We include studies that explicitly focus on MSMEs in the formal, as well as informal sector. We limit the analysis to urban, as well as rural non-farm employment and firms, i.e. farms and employment on farms are not considered. Although, there are no common criteria that are applied uniformly to identify MSMEs, neither by researchers nor by statistical offices, we use an employment criterion and set the threshold at 250 employees. As micro-enterprises we define firms with less than five workers. Firms are considered being in the category small if they have between 5 and 19 workers and medium sized firms are firms with 20 and more workers (but less than 250). Evaluations of interventions that target the labor force directly are only included if the intervention was implemented to enhance the creation of new MSMEs (incl. self-employment). Our systematic review is focused on the context of developing countries. We use the thresholds of the World Bank and consider countries as developing countries if they show a GNI below USD 12,476 per capita, calculated using the World Bank Atlas method. Thereby, we look at low and middle income countries. Specifically, the following income groups provided by the World Bank classification are included: low income (USD 1,025 or less per person and year), lower middle income (USD 1,026 - 4,035), and upper middle income (USD 4,036 12,475).

We define employment creation as the emergence of new jobs in existing MSMEs (whether privately or publicly owned) and as jobs that arise through the creation of new MSMEs. The latter also includes self-employment. Whenever a certain intervention creates some and destroys other jobs simultaneously, we explicitly consider - if the data allows - both gross and net employment generation. However, very often only one of the two is available. We consider any form of employment under acceptable working conditions, conditional on the specific context studied. This includes paid employment, as well as paid and unpaid family employment. ${ }^{1}$ The outcome can be measured in the number of employees or its growth rate. Studies are not included if they focus exclusively on hours worked, labor intensity, wages or labor supply without considering employment per se.

\footnotetext{
${ }^{1}$ The latter usually implicitly paid.
} 
Based on an initial screening we decided to classify all studies into five intervention categories: access to finance, entrepreneurship training, research and development, business development services, and private sector incentive schemes. In addition to these specific programmatic interventions, we also decided to include studies that analyze the impact of more general conditions, generally referred to as the business environment on MSMEs (policy interventions) as long as it was possible to establish causality between the policy and employment creation in a credible way.

Studies are included if they can establish a credible causal relationship between a programmatic or policy intervention and job creation in MSMEs. Hence, we include studies if they consist of an impact evaluation based on an experimental design such as a randomized controlled trial (RCT), as well as on quasi-experimental designs including propensity-score matching, instrumental variables, regression discontinuity designs or difference-in-difference estimation. For quasi-experimental designs, we include studies that are based on panel data as well as cross-sectional data, analyzed either at the firm or individual level. We only include studies that report quantitative impacts.

Moreover, inclusion/exclusion is not based on publication status. If an identified study was still ongoing, the authors were contacted in order to check whether the results were already available for inclusion into this review. Evaluations in any of the five following languages are included: English, Spanish, French, Portuguese, and German.

\subsection{Search methods to identify relevant studies and data extraction}

A range of different search methods have been applied to ensure the identification of recent, ongoing, as well as unpublished studies. These include the searching of electronic databases, screening of relevant websites, hand-searching of key journals, literature snowballing, and contacting researchers and key experts in the topic. Details on the search strategy can be found in Appendix A. Further details are provided in Grimm and Paffhausen (2014).

Information from the included studies has been extracted systematically. The information extracted consisted of the general information of the study, i.e. author(s), title, year and type of publication. Furthermore, the country or countries and the target population were characterized for each study, as well as the outcome(s) measured and the type(s) of intervention. With respect to the type(s) of interventions, we recorded whether the intervention was a stand-alone or joint intervention. If it was the latter, the different components of the intervention have also been documented. Whether employment or firm creation was a primary objective of the intervention was also recorded. Furthermore, included studies were characterized according to their study design, comprising methodology, sampling methodology, sample size etc. Finally, information regarding the internal and external validity was extracted from the studies. Data extracted from included studies, especially those involving judgments by the coder, have been discussed extensively among the two researchers involved.

\section{Theory of change}

The considered interventions affect firms and prospective firms in many different ways. Some relax capital market constraints, others improve management skills and business practices, again others reduce the cost of labor or ease formalization procedures. The figure below shows a simplified result chain for all interventions together. Next to the final outcome of interest these chains also show intermediate outcomes such as investment, productivity, output and profits. For all interventions it is obvious that employment does not necessarily have to respond. If capital market imperfections are relaxed and investment increases, employment effects will only occur if the investment is large enough and if labor is a complement to the investment and not a substitute. Labor saving investments could even reduce employment. Credits that are used to increase inventories are also unlikely to increase employment. Interventions, such as training, that increase the productivity will only have employment effects if output is increased following falling costs. Hence, the price elasticity of demand and the degree of competition matter. In other words growth at the intensive and extensive margin needs to be distinguished. Only the latter goes hand in hand with more employment. Yet, if 
employment is not increased, increasing productivity may secure survival of the firm and therefore prevent jobs from disappearing, so in that sense it would also imply a contribution to employment.

[Figure 1 about here]

Employment effects also require that labor supply is sufficient, i.e. that workers queue for jobs and can be hired at any time. An assumption that is probably realistic for most urban areas in the developing world at least as long as unskilled workers are concerned. If skilled workers are concerned this might not always be a good assumption. Some interventions may also imply negative externalities on nonbeneficiaries. In a context in which economic growth is weak or completely absent an increase in productivity in one firm may drive another firm out of the market and hence the net job effect might be zero, or at least reduced.

Temporary wage subsidies will have lasting impacts only if the subsidized job or 'on the job training' increases the worker's productivity to such an extent, that the firm continues hiring that person even if the subsidy expires. This would imply that the temporary subsidy allows reaching a higher growth trajectory that would not be reached without the subsidy. Obviously such programs may also work because they solve a behavioral bias, i.e. it may provide a hiring incentive to those that are very risk averse and reluctant to hire, although it would be beneficial for them.

A simplification of registration procedures will only have any effect on employment if the registration allows to access new markets or to reduce the costs of certain inputs, such as public services or if it improves the access to finance. But even then the above mentioned caveats apply.

Finally, it is important to note that these result chains have been developed from the perspective of the evaluator, based on the objectives of proponents of such interventions, which justify them on the basis that they eventually contribute to employment creation. They are however not necessarily the result chains of the implementers of such interventions and most certainly they are not the result chains of the beneficiaries. For instance, an NGO delivering a microcredit program might do this with the aim of promoting female empowerment or increasing household income only. A researcher who evaluates this program then however might assess the effect on a broad range of outcomes, including employment in household enterprises. The person obtaining the microcredit might be interested in merely smoothing consumption, keeping her business going or creating a new subsistence activity but not necessarily to employ more staff.

\section{Search procedures and results}

\subsection{Search and identification}

We organized our search strategy around two alternative search approaches. The first approach combined sets of search terms referring to the population, outcome and type of study and was conducted between February 5 and February 20, 2013. This search resulted in 1,200 hits. After removing duplicates, there were still 932 records left that needed to be screened. The second approach focused on the different intervention categories considered in this systematic review and was carried out from May 13 to June 16, 2013 and resulted in 2,446 hits. A substantial number of these were again duplicates, so that after removing them, there remained 1,343 records to screen.

We then merged the results of both search approaches, which together amounted to 2275 hits. Again, duplicates had to be removed so that the final sample included 1924 records. These records were screened successively, applying inclusion criteria, in a first step, to titles and abstracts only. This was done mainly by one researcher. However, in order to minimize bias, a second researcher randomly double-screened about a quarter of the studies that had been excluded by the first researcher. There were virtually no discrepancies in judgment for this sample of studies. Moreover, unclear cases were screened additionally by the second researcher, and where necessary, a conclusion was reached through discussion. Thereby, already about 85 percent of studies could be excluded. It was not always possible to reach a decision based on only the title and abstract of a study. In those cases, we resorted to screening the text. Overall, the texts of about 300 studies were screened to reach a final decision on 
eligibility and eventually inclusion. A common reason for early exclusion of studies was that they did not focus on low and middle income countries. In addition, although many were concerned with SMEs or smaller enterprise, these were no impact evaluations and typically did not document any changes in the outcomes relevant for this review. Obviously, a non-negligible part of the papers was also totally off topic.

The whole procedure left 139 studies for thorough full text screening. Out of these, four records could not be obtained in full text. However, further cross-checks suggested that they were, with a very high probability, irrelevant for the purpose of this review. There was one study that was judged highly relevant based on the abstract, but the study could not be obtained. The database search also identified 15 potentially relevant ongoing impact evaluations. We hence contacted the authors in order to see whether any preliminary results were already available. As of February 15, 2014 we had received information on the status of five ongoing impact evaluations. None of these however were in a stage in which any findings could already be included in our review. Since up to this point, we had not yet identified a single study for inclusion which had been conducted before 1990, we decided to definitely exclude studies that had been conducted before that date. For all remaining papers the final decision on inclusion or exclusion was always based on the full text of the study. Finally, 34 studies were included from the database search. ${ }^{2}$

The screening of websites of key donors and funders of MSME interventions, as well as research institutions resulted in one further study that was included. In addition to the database search and website screening, a number of relevant academic journals were searched for studies to be included. This enabled us to identify three more studies to be included. Literature snowballing of the World Bank World Development Report 2013 and other (systematic) reviews resulted in four more records that were included. The references of included studies were thoroughly screened, resulting in ten more studies to be included in the review. Furthermore, we contacted key researchers and provided them with a preliminary list of included studies as of September 9, 2013, asking whether they were aware of any further studies that met our inclusion criteria which we should include in the review. We received answers from three researchers as of February 15, 2014. This exercise resulted in no further study to be included in the review. Finally, two studies were included in the review that were already known to the authors but had not been identified through any of the sources mentioned above. Altogether, this comprehensive search process hence led to a final sample of 54 studies that have been included in this review. The entire process is illustrated in Figure 2.

[Figure 2 about here]

\subsection{Short characterization of included studies}

\section{Population and context}

The 54 studies included in this review cover a wide range of countries from all major world regions. The majority of studies focuses on Latin America. This can be explained by the fact that in particular Latin American countries have experimented a lot with active labor market policies over the past two decades and that they have earlier than others started to rigorously evaluate many of their policies. Interestingly, the share of studies that have been conducted in Sub-Saharan Africa is with nine studies larger than we had initially expected, but it still constitutes only a small evidence base, given that employment creation is a major preoccupation and considerable amounts of foreign aid are spent on private sector development in that region. Most studies have been conducted in upper middle income countries (32) and lower middle income countries (15). Only 7 studies took place in low income countries. The majority of the studies focus on micro-enterprises (with up to five employees). In this category we also included studies that target individuals and households with the aim of creating new microenterprises or enhancing self-employment. A total of 36 studies fall into this group. Another 18 studies target larger firms, which could be categorized as small and medium sized enterprises. These are generally already established and mostly registered (i.e. formal) enterprises.

\footnotetext{
${ }^{2}$ Note that the second search approach described above led to a contribution of only three additional studies to that sample that were not found by the first approach, giving us confidence in our search strategy.
} 
[Table 1 about here]

\section{Interventions}

Most of the studies in our sample analyze interventions that aim to remove credit constraints of micro, small and medium sized firms (26). All but two of them imply the provision of capital, either in form of micro- and larger loans or through the provision of cash- and in-kind grants. Some of the interventions focusing on access to finance are also combined with other interventions. In most cases these are entrepreneurship training interventions. For the sake of completeness such interventions are analyzed below in both groups - finance and entrepreneurship training - whenever justified, based on the specific features of the intervention evaluated. The sample of studies focusing on entrepreneurship training includes 20 studies. The interventions covered are somewhat diverse in that they consist of general business and financial literacy trainings, as well as more customized and specialized support, or even vocational training with the aim of developing these skills for self-employment. They also differ regarding the duration of the treatment and sophistication of training content. For the other categories, the samples of included studies are all relatively small. There are six studies in the area of business development services. The interventions analyzed in these studies are very heterogeneous; they include for instance counseling, supplier development, product and process innovation, and the provision of working premises. We identified only one relevant study related to research and development. Since the intervention evaluated in this study had many features of business development in general, we decided to review the study together with the five other studies we had identified in the area of business development services. The studies focusing on private sector incentive schemes to enhance employment all rely on wage incentives. Overall we found four relevant studies to be included in this review. Three of them assess the impact of wage subsidies on MSMEs, while one study looks at the effect of minimum wage legislations. They are also analyzed jointly with business development services and research and development. Finally, we identified five studies that assess interventions falling into the category of improvements to the business environment. These studies all deal with interventions to achieve formalization of MSMEs and the impact of formalization on employment creation.

\section{Outcomes and impacts}

As set out before, we included studies that assessed the impact of interventions relevant to MSMEs on either changes in employment levels in these enterprises, or the creation of new enterprises, including becoming self-employed. There are also studies that assess the impact on both outcomes which were then also both used. We always extracted the evaluators' most preferred estimate. Robustness checks were considered to assess the quality and reliably of the estimates, but are not retained for the meta regression analysis below.

Some studies provide impacts at different points in time, such as short-term and long-term impacts. Others offer impacts for stand-alone and mixed interventions. In these cases we have more impact observations than studies in our sample. Hence, from the 54 studies we included in this review, we have a total of 116 impact estimates. Most of the impacts we retrieved (about 60\%) represent the impact on employment in treated firms. The remaining impacts measure business creation and selfemployment. We do not consider explicitly firm survival as only few studies provide results for this outcome. We express impacts in terms of their standardized mean difference (SMD), i.e. as the ratio between the change in the outcome due to the intervention divided by the standard deviation of the outcome in the control group (or at baseline). If the outcome is a binary outcome such as 'having set up a firm or not' we use the risk ratio. In those studies where such impact measurements were not directly provided (in fact the large majority) we computed them ourselves. However, some studies do not provide all the necessary information, in these cases we based the estimate just on the reported $t$ values of the impact and the sample sizes of treatment and control groups using the formulas given in Lipsey and Wilson (2001). Using different computation methods, on the one hand, reduces the comparability of the estimates. On the other hand it limits the number of studies for which no effect size can be computed. 


\section{Study design and methods applied}

Of the 54 studies that have been included in this review, 28 studies employ quasi-experimental designs while 26 studies are based on RCTs. RCTs are especially relevant for impact evaluations in the area of entrepreneurship training and finance. Only one fourth of the studies that evaluate the impact of entrepreneurship training use a quasi-experimental design. Studies that assess finance interventions are divided relatively evenly across different study designs, with 13 studies employing an experimental design and another 13 an RCT. Within the group of RCTs, the studies focus exclusively on microenterprises and potential entrepreneurs. Note that this is also the case for the entrepreneurship training interventions. The RCTs have all been emerging in the recent years, and a number of studies are ongoing at this moment. This shows the high interest in credibly establishing the impact of popular interventions such as microfinance, as well as increasing possibilities to conduct such trials in this area. Studies included in the areas of business development services, wage subsidies, and business environment, almost exclusively rely on quasi-experimental designs such as difference-in-difference, propensity score matching or instrumental variables to deal with possible selection effects.

\section{Synthesis of the evidence}

\subsection{Access to finance interventions}

Most of the 26 studies that are concerned with finance interventions examine the effectiveness of microcredit schemes (20 studies), followed by conditional or unconditional cash- or in-kind grants (four studies) and two studies that just introduce changes to existing credit schemes, such as Field et al. (2011), who evaluate the extension of the period until the first repayment is due and de Mel et al. (2013b) who provide savings incentives. Not a single study could be identified that looks at the employment effects of micro-insurance. All studies are listed and briefly presented in Appendix B. Some of the interventions analyzed here are stand-alone interventions, whereas others are combined with entrepreneurship training or other interventions with a completely different scope. This is for instance the case in the study of Tarozzi et al. (2013), where microcredit is combined with family planning services. The amount of finance involved is typically between USD 100 and USD 2,000. By definition micro-credit programs target poor households and micro firms. This must be taken into account when compared with other types of finance interventions that target larger enterprises (small to medium sized firms), which are already formalized, with the aim of expanding these businesses. The range of these studies reflects well the dominance of micro-credit in the debate about firm support as well as the common belief that limited access to financial services is a major constraint for the expansion of micro, small and medium enterprises. However, it should not be forgotten that the range of studies was limited by the interventions' (quasi-)experimental evaluability. Interventions to overcome financial impediments via developing financial markets in general, for example by extending refinancing maturities for banks, were not covered.

With respect to employment creation most micro-credit schemes turned out to be rather unsuccessful; only 16 out of 45 impact estimates, which were measured in the 26 studies on access to finance, show a statistically significant increase in employment or firm creation. 27 out of the 45 treatment effects were not statistically significant. In two cases, a statistically significant negative effect was found. The sign and significance of program effects can be found in Appendix B. Table 2 provides the distribution of effect sizes. The generally small, and often statistically insignificant, effects reflect of course also the often very low power of these evaluations. In some studies power is further reduced by rather low program take-up rates. Positive effects on employment, if found at all, were only small, especially for already existing small and micro enterprises. Major effects were achieved with respect to the creation of new (mostly micro) enterprises and the expansion of already larger, well established and profitable firms. The success cases are more concentrated in (upper) middle income countries rather than low income countries, where the focus however is mainly on small to medium sized firms that are already established and not micro-credit programs but rather larger scale public credit lines and guarantee schemes. Yet, those interventions are predominantly evaluated using quasi-experimental study designs which may, on the one hand, imply that selection effects could not be eliminated entirely, or, on the 
other hand, that these evaluations often rely on larger samples and less heterogeneous firms which increases the power of these analyses and hence the probability of detecting significant effects.

[Table 2 about here]

Apart from power considerations, the high proportion of statistically insignificant results does not necessarily reflect the futility of this measure but is probably due to the fact that employment generation is typically not a primary objective of micro-credit programs. Rather, income stabilization most frequently seems to be the major intention. Most enterprises make use of the credit or cash grants, if directly offered, but the studies' findings suggest that the financial resources are primarily used as working capital, i.e. invested into inventories. Only on rare occasions would these result in fixed capital investments in machines or buildings. De Mel et al. (2013b) for example detect a significant effect of a savings scheme on investment in inventories, while there is no significant effect on fixed capital investment. Likewise Arraiz et al. (2012) find that credit had no impact on capital stocks and suggest that firms use credit rather to increase their working capital. Hence, such interventions might have no employment effects, but in many cases they show significant impacts on sales and revenues.

With regard to business profits, the majority of studies does not detect an impact (see Angelucci et al., 2013; Augsburg et al., 2012; Barnes, 2011; Crepón et al., 2011; De Mel et al., 2013b; Karlan and Zinman, 2011; and Nelson, 2011). Karlan et al. (2012) find that a capital grant even lowered profits, while Banerjee et al. (2013) detect a positive impact, but only for existing, relatively larger and the most profitable microbusinesses. Only Marcours et al. (2012) find that cash grants for investment resulted in higher profits from non-agricultural self-employment activities more generally. These effects were substantial even two years after the end of the intervention.

It is debatable whether the limited evidence for an improvement in business profits is due to rather short follow-up periods. Of course, it might be that it takes some time for the entrepreneur to be able to use the capital treatment effectively and adjust accordingly in order to reap the benefits of increased investment. However, as Augsburg et al. (2012) argue, most microenterprises are very simple in nature so that it should not take all too long to generate profits as a result of the investment. It also turns out that most loans seem to be simply too small and their maturities too short to lead to large changes in the capital stock and the production technology. For instance, a tailor who - thanks to a micro-credit switches from a mechanical to an electric sewing machine may neither have the need nor the profitability to immediately hire an additional worker. Nevertheless, he may well see an increase in performance as measured by revenues, profits and, of course, business investment. Hence, we find growth at the intensive rather than at the extensive margin. Field et al. (2011) indirectly provide supportive evidence to this hypothesis in showing that the details of the loan contract matter. They find that short repayment periods, which over the loan period translate into lower outstanding loans and shorter maturities, prevent poor entrepreneurs from investing since they fear not being able to repay on time (Field et al., 2011). Moreover, in the cases where potential business starters or subsistence-type of enterprises are targeted, a reason for failure may obviously also be that very often there are competing needs and hence instead of investing, borrowers spend the credit on health care, education, housing improvements and so on. Based on such insights Karlan and Zinman (2011) suggested that microcredit may need to be combined with detailed business planning and extraordinarily close monitoring in order to assure that it leads to increased investment in the business.

Programs targeting particularly women also appear to be less successful in employment creation than programs without such a focus. This suggests that women face additional constraints which need to be overcome in order to increase the return to finance. Mothers, for instance, tend to spend on average more on food, clothes and health for the household, when compared to fathers, and may therefore have less to spend on capital goods. Resisting pressure from family members and relatives to share financial resources might also be more difficult for women, obliging them to share funds even when they would prefer to invest. In many settings, women still have lower education than men, they have no access to formal banking services without consent of their husband, they have no property rights and are not allowed to leave their house alone. All these factors may explain why, on average, loans to women have lower returns than loans to men. 
Finally, most of the studies in this sample generally assess the effect at one point in time. A notable exception is De Mel et al. (2013b). They observe treatment effects at seven different points over a horizon of two years and conclude that positive effects on business performance arise only in the short-run, suggesting that the savings program speeds convergence to the steady state of the businesses but has no transformative effect by changing the long-term steady state of the business itself. So in the end, while the interventions may not be able to increase profits or employment in existing enterprises, they nevertheless may have an important impact on securing the continuation of existing businesses, thereby also contributing to employment protection.

\subsection{Entrepreneurship training}

The second most frequent intervention category in the retained sample was entrepreneurship training. The review includes 20 studies that fall into this category (see Appendix B). Training measures comprise business skills training, business plan development, financial literacy training, technical and vocational training (in-class and on the job), and life skills training. Hence, not surprisingly, even within the category of entrepreneurship training interventions the heterogeneity is quite substantial. Entrepreneurship training provided to beneficiaries varies in that it can be either general, or specifically tailored to the businesses and difficulties of the beneficiaries. Most evaluations assess the impact of general entrepreneurship training in the areas of business management, accounting, financial literacy or the development of vocational skills (15 cases). Bandiera et al. (2012), for instance, analyze the provision of vocational training in activities like hair-dressing, tailoring, computing etc. to adolescent girls. Other examples can be found in Bruhn and Zia (2011), Calderon et al. (2013) and de Mel et al. (2012), who assess interventions that provide general business and financial education trainings to microcredit clients and individuals interested in starting a new business. A few interventions provide more specifically tailored assistance (4), which may come in the form of business plan development assistance (see Klinger and Schündeln, 2011; Jaramillo and Parodi, 2003) or management consulting services focusing on problem diagnosis and solving (see Bruhn et al., 2013). One study analyzes both, an intervention that provides general business training to microentrepreneurs as well as the combination of this general training with individualized support (see Valdivia, 2011). The interventions analyzed here further vary substantially regarding their duration. While some training courses are delivered over a few days only (see for instance Bruhn and Zia, 2011), others are more substantial. The business training evaluated by Valdivia (2011) for instance was delivered over twelve weeks in three sessions per week that lasted three hours each. Vocational entrepreneurship training tends also to be more substantial in duration, varying further with the specific occupations for which the training is provided.

From this sample of studies it appears that skill constraints are believed to be more relevant to microenterprises than for already established SMEs: the majority of interventions targets microenterprises with up to five employees or aims to enhance self-employment in groups highly at risk of unemployment, such as the youth. Often entrepreneurship training interventions, especially when provided for business start-up, are delivered jointly with start-up finance, indicating that skill constraints are typically not assumed to exist in isolation. The majority of studies included here are based on RCTs; only five employ a quasi-experimental design. All together 25 treatment effects were analyzed.

Looking across all studies, 11 out of 28 treatment effects show significant positive employment effects (see Appendix B). 17 treatment effects were not statistically significant. As for finance interventions, low statistical power of many evaluations is probably partly causing the large number of null results. Interestingly, a few studies found negative employment effects. Drexler et al. (2013) found that training led to a reduction of employees for low-skilled business owners, and Valdivia (2011) as well as Calderon et al. (2013) found microentrepreneurs that participated in general business training to be more likely to close poorly performing businesses. This suggests that entrepreneurship training enhances the entrepreneurial spirit and forces (potential) entrepreneurs to think more carefully about the business model and its profitability. In fact, even non-existent or negative employment effects can be good news for trainings' effectiveness as entrepreneurship training was found to help nonprofitable firms either to become profitable or to close down. Likewise, entrepreneurship training can prevent non-profitable business ideas from being started. 
Overall, most training interventions have difficulties in changing actual business performance like profits. Yet most programs produce significant improvements in business skills and behavioral skills, and sometimes also higher optimism and motivation, although some of these changes might be due to a changed reporting behavior after the start of the intervention (Drexler et al., 2012). Thus, employment seems to come last in the result chain of entrepreneurship training. Some studies report higher investment, very few studies report process or product innovations and sometimes also improvements in sales and revenues. Even fewer studies measure higher profits and, fewer again, employment. Furthermore, short-term positive effects often seem to vanish in the long run.

There are no straightforward results on the influence of targeting. The evidence is mixed on whether trainings' return is higher for those with initially lower skills and whether it is more helpful for male or female owned enterprises. The review suggests that training is more helpful for start-ups than for business expansion. However, since many interventions that aim at business start-up often also include some form of financial assistance, it is difficult to isolate the effect of the training. De Mel et al. (2012) for instance find the combination of a cash-grant with entrepreneurship training to be especially successful; also because it led to the creation of more successful businesses. The more tailor-made and substantial the training the better, but it is not necessarily the more-complex programs that are the most successful. Drexler et al. (2013) for instance observe that general accounting training led to some improvements in objective reporting quality and business performance for higher skilled participants, but had the opposite effect for less educated individuals, while a simpler, rule-of-thumb training was more effective for those participants with lower educational levels. From the studies it further appears that training needs to address specific knowledge gaps and be 'substantial' in order to be effective. The consulting and mentoring services analyzed by Bruhn et al. (2013) eventually led to increases in the number of employees of treated businesses. These services were provided to beneficiary enterprises over a period of one year, in weekly four-hour consulting sessions. Likewise, Premand et al. (2012) find positive treatment effects of an intervention that is provided over a period of one academic semester.

\subsection{Business development services and wage subsidies}

In this sub-section we cover a set of ten studies, which are rather heterogeneous in the specific nature of the underlying interventions (see Appendix B). Broadly, they fall under the heading of business development services and targeted subsidies. Four of the ten studies cover business development services in the narrow sense (supplier development, support for environmental audit, provision of working premises, etc.). One of these studies covers conditional tax-breaks and fiscal incentives for technological innovations as well. Two further studies measure the employment impact of grants for product and process innovations. An additional three studies cover supply or demand side wage subsidies, and one study measures the impact of minimum wage legislation on employment. All the studies on wage-related interventions focus on Turkey or South and South-East Asia, while the other studies cover almost exclusively Latin-American countries. Only one of these ten studies is based on an RCT design, while the others use a quasi-experimental approach or exploit the variation in the policy across time and space to identify effects.

The studies show mostly positive and statistically significant employment effects (see Appendix B). Nevertheless, general conclusions have to be treated with care due to small sample sizes and selection biases that are possibly not entirely removed by the evaluation design. Overall it seems that business support services and targeted subsidies can contribute to employment generation if they are demand driven, tailor-made and focused. Larger firms may need quite specific and sophisticated support, whereas small firms just need very rudimentary improvements to their business.

Interestingly, Kluve (2010) who compared the effectiveness of active labor market programs across European countries came to a very similar conclusion as we do: The direct employment effects were the largest for wage subsidies and 'services and sanctions' conditional on certain productivity enhancing activities. According to the studies we reviewed, tax-breaks and fiscal incentives conditional on process and product innovations seem to be particularly effective. However, the robustness of the findings is somewhat low, first, because the sample of studies is quite small and, second, because almost all studies have to rely on a rather weak identification strategy and hence a 
bias through firms selecting themselves into such programs cannot be ruled out completely. It is also remarkable that nothing can be said about the East- and South-East-Asian context, where at least in some countries business support services may have played an important role.

The studies on wage subsidies suggest that targeting matters for job creation. Two different programs that have been examined in a similar context in Turkey allow for an interesting comparison of supply and demand driven subsidies. One program targets the employers who benefit from reductions in social security contributions for additionally hired workers. This was found to increase the rate of employment growth and business growth substantially (Betcherman et al., 2010). A supply-driven program through which workers received the subsidy in the form of vouchers that allowed them to be hired and get training on the job, turned out to not increase employment chances. Only a few beneficiaries were retained in their job once the subsidy came to an end (Fretwell et al., 1999). Various reasons could explain why this program failed. One could be that this has to do with the targeting. The on-the-job training program targeted employees whereas the more conventional wage subsidy programs targeted employers. Employers may keep workers hired at a reduced rate, when they are free to choose the workers they actually prefer. If an unemployed person applies for a job with a voucher, not only may the profile not fit, but a voucher may have a negative signaling effect. Hence direct wage subsidies may have more positive employment effects than voucher based-programs. However, they may have very different income distributional effects. These interpretations are based on only two studies and eventually, whether they are really valid can only be found out if several wage subsidy programs test and compare such specific design features.

Finally, it is obvious that wage subsidies are in general a quite expensive intervention and the programs covered here are no exception. The pure wage subsidy program in Turkey entails costs per job-month created that correspond to roughly $94 \%$ of the total cost of employing a minimum wage worker. This may still seem acceptable, if the jobs created are sustainable, but evidence whether this is really the case is scarce (Betcherman et al., 2010). A major cost component is the dead weight loss produced by the fact that many workers that are hired under a subsidized rate would have been hired anyway. This is also confirmed by the experimental study in Sri Lanka (De Mel et al., 2013b and 2010), where the authors find a strong correlation between pre-program hiring intentions and program uptake.

\subsection{Interventions to promote formalization}

In most low and middle income countries the bulk of urban micro and small enterprises are informal, i.e. they are not registered with the tax authority and operate outside most regulations. A key policy question is whether the performance of these firms could be improved and their size in terms of employed capital and staff be expanded through formalization. On the one hand, it is believed that formalization increases access to credit and other resources important for business success and expansion, even if some argue that most micro and small firms have little to gain here because their business is simply too small to benefit from any services offered to formal firms and in many countries the government has not much to offer anyway (Maloney 2004). On the other hand, formalizations could imply a significant increase in tax payments which have to be added to the bureaucratic act of formalization, which according to De Soto (1989) already can be so significant that they alone prevent firms from becoming formal.

As both costs and benefits of formalization are involved, the policy problem of formalization is twofold: What interventions are suited to enhance firms' formalization, and what are the effects of becoming formal? As this review focuses on employment effects, formalization studies were only included if they covered effects on employment. Five studies were identified that can credibly establish a link between formalization and employment (see Appendix B). Four of them concentrate on Brazil and Mexico, where significant reforms have been implemented to reduce the costs of formalization. The fifth focuses on Sri Lanka and is based on a randomized field experiment where cash rewards are offered to firms if they formalize.

All studies show that it is difficult to get the average firm formalized as it is simply too small and not profitable enough to make use of the potential that formality offers. Programs that offer cheaper and 
easier formalization procedures seem to work for a relatively small group of entrepreneurs and firms that show already a higher initial performance. It also seems easier to formalize firms while they are being set up than formalizing firms that already exist. This has in particular been shown in the case of Mexico (Bruhn, 2011). De Mel et al. (2013a) showed for the case of micro and small firms in Sri Lanka that even if the equivalent of one month of the median firm's profits are offered only around one-fifth of all firms register the business. Interestingly, in this particular case the lack of property rights for the ground they work on was a major deterrent to formalization for many entrepreneurs. Complementary evidence comes from Andrade et al. (2013), a study not included in our systematic review because it does not assess employment effects, who directly tested the effectiveness of various treatments intended to increase formality in Brazil based on an RCT . They found that more information on procedures and lower costs did not work either; only inspection visits had some effect. Receiving an inspection gave a 21 to 27 percentage point increase in probability of formalizing.

In Brazil and Mexico, among those firms that do formalize, performance in terms of revenue and profits typically improves, including employment and capital investment, but for most only modestly. For Sri Lanka, De Mel et al. (2013a) do not find any employment effects as a result of formalization. ${ }^{3}$ Of course, it will always increase the government's tax revenues, which is typically the main objective of formalization anyway. Yet, it seems that programs that "force" firms to formalize are unlikely to produce any significant employment effects as for many formerly informal firms formality does not translate into extra profits but into additional costs. It seems the best incentive governments can provide for formalization is to offer useful public services in return. This does of course not imply that policies should not simplify administrative procedures, but efforts need to go beyond. It is not the costs of registration but the expected benefits of formality that is pivotal for the decision to formalize and only if such benefits exist it is likely that formality also leads to additional jobs.

\section{Meta-regression analysis}

\subsection{Method}

To implement a meta-regression analysis we use two alternative impact measures: first, whether a given intervention had a positive significant impact on employment, firm ownership (start or continuation) or self-employment; ${ }^{4}$ and, second, the standardized effect size. How we derived the latter was explained above. Relying on standardized effect sizes ensures a certain comparability of impacts across studies. However, measured impacts still differ in terms of the temporal horizon they refer to and of course in the program costs that had to be incurred to produce a particular change in the outcome.

For the sets of estimates where we just use a binary variable taking the value one if the effect of program $i$ was significantly positive, we run a simple probit regression and explore the variation of that binary variable across large set of study characteristics $X_{i}$. Hence, the model reads:

$$
\operatorname{Probit}\left(y_{i}=1 \mid x_{i}\right)=\theta\left(X_{i}{ }^{\prime} \beta+\varepsilon_{i}\right),
$$

where $X_{i}$ includes the type and characteristics of the intervention, the term, $\varepsilon_{i}$, is the error term and $\theta$ stands for the cumulative normal distribution. Since coefficients of a probit model cannot be directly interpreted, we compute and show marginal effects, i.e. the change in the probability of success if one explanatory variable is increased by one unit while all other explanatory variables are kept at their mean. Since some studies contribute with more than one outcome, we correct the standard errors for within-group correlations. The application of weights ensures that each intervention counts only once in the sample.

We further conduct simple linear regressions, where the dependent variable is the standardized effect size. The regression model reads:

$$
y_{i}=X_{i}^{\prime} \alpha+\eta_{i}
$$

\footnotetext{
${ }^{3}$ Similar evidence comes from McKenzie and Sakho (2010), but they do not focus on employment effects.

${ }^{4}$ Since we had only four statistically significant negative impact estimates in the sample, we decided to lump together insignificant and statistically significant negative estimates.
} 
On the right hand side we use the same explanatory variables as in the probit model above. The term $\eta_{i}$ captures the unexplained part of the variance in $y$ including measurement error.

As explanatory factors we include the type of the intervention, whether the intervention explicitly aimed at employment creation, whether it was provided in combination with other interventions, whether it targeted women, the types of enterprises targeted, the study design of the impact evaluation, as well as the country income category, and finally, the outcome measure, i.e. whether it is employment or firm ownership. Table 3 below shows the summary statistics for the dependent and explanatory variables. We also considered testing whether the type of the implementing agency plays a role, for instance whether this was a public or private entity. However, this did not lead to any meaningful results. First many studies are not clear about the status of the implementing agency. In other cases the implementing agency might be private, but the intervention was developed and designed by a public agency, which at the end makes it hard to interpret the results. Apart from that the sample size also puts a limit on the extent heterogeneity - in particular in terms of context and program characteristics - can be captured by the Meta-regression analysis.

[Table 3about here]

In total, we have 116 observations that can be used for the meta-regression analysis. 40 percent of these relate to business creation while the remaining relate to changes in employment in existing firms. Overall, 46 percent of impact estimates are positive and statistically significant at the 10 percent level. Most impact estimates relate to the effect of finance interventions, followed by training interventions. About 12 percent of impact estimates represent the impact of business development services, wage incentives and policies to enhance research and development. Interestingly, around 70 percent of the estimates come from evaluations of interventions that explicitly aimed at creating employment or new enterprises. Almost half of the impact estimates come from joint interventions, and more than half of the impact estimates have been obtained through randomized controlled trials. Furthermore, the majority of evaluations focused on existing and potential microenterprises and was conducted in upper middle income countries.

\subsection{Results}

Looking at the effectiveness across the different intervention categories, it can be seen that the included finance interventions had on average lower employment effects than the included training interventions (see Table 4). This is confirmed by both specifications, i.e. whether we use the dichotomous outcome or the standardized effect sizes. There are however, no systematic and significant differences between training interventions and business development services, wage incentive schemes and interventions that improved the business environment.

In our sample, there is some indication that interventions of the type we consider have often more chances in establishing new firms than expanding existing firms. A micro-credit program, for example, may enable many households to start a small business, but may enable only few established microentrepreneurs to expand their business. However, as McKenzie and Woodruff (2014) pointed out, this finding may partly be due to the fact that power is generally higher for detecting binary outcomes (such as whether a new business started) than for detecting changes in rather continuous variables (such as employment). Those interventions that target small enterprises appear to be more successful in achieving significantly positive employment effects as compared to those that target microenterprises, implying that only a small share of microenterprises graduates, or that it is at least difficult to expand microenterprises in general. The 'IFC Jobs Study' comes to a similar conclusion based on a review of the literature (IFC, 2013). However, since specific types of microenterprises might still have the potential to grow, targeting is crucial.

\section{[Table 4 about here]}

Surprisingly, whether employment creation has been an explicit objective of the evaluated intervention does not correlate with larger employment effects. Combined interventions did also not systematically lead to larger employment effects, although we had seen above that the specific combination between finance and training often seems to work better than each of these two interventions in isolation. 
Those interventions in our sample that targeted women specifically apparently had a lower chance of success, although this finding is only statistically significant in some specifications. This is consistent with a number of recent studies that find capital or business training to have no effect on female enterprise performance (see for instance de Mel et al. 2009; Fafchamps et al., 2011). Yet this does not mean that the return of targeting women is lower, it rather suggests that programs targeted at women typically need to account for other, complementary constraints as well. For instance, if women have less control over their budget than men, then cash grants paid to women have a lower impact on investment than for men. Women typically also have lower levels of formal education, have often only limited access to other relevant services, often need to work from home and are often deprived of property rights - land rights in particular.

Finally, the regressions also reveal that programs that have been evaluated experimentally show fewer significant employment effects than programs that have been evaluated with quasi-experimental methods. Looking at finance interventions, for example, shows that 20 out of the 26 treatment effects that are based on an RCT show insignificant effects, while this is the case for only 8 out of the 18 treatment effects based on quasi-experimental methods. Hence, the failure rate is almost twice as high. Obviously, the most intuitive explanation is that the quasi-experimental studies cannot entirely deal with selection effects and hence employment effects are often over-estimated. We constructed further variables measuring the risk of bias, based on our own assessment for various dimensions of internal and external validity and following the criteria proposed in Waddington and Hombrados (2012). Although, low statistical power of many RCTs is an important shortcoming controlling for this problem and other risk of biases could not substantially reduce the estimated coefficient associated with RCTs. However, investigating the included RCTs in more detail also shows another potential explanation: RCTs systematically focus more prominently on small programs, very poor areas and very specific target groups (as compared to evaluations based on quasi-experimental designs), all of which may increase the probability of a failure. In other words, RCTs are often applied in very specific cases and hence one needs to be careful to generalize their findings.

\section{Conclusion}

Overall the review shows that creating and enhancing employment is a very complex challenge. Many conditions have to be met before interventions in favor of individual enterprises do not only improve business performance but also lead to additional jobs. Phrased differently, it is typically 'a long way' in the result chain from policy inputs to employment impacts, even more so if employment is supposed to be sustainable and tied to acceptable and secure working conditions. Given the discrete nature of decisions to found a new business or to hire an additional employee, not a minor change but rather a major push is needed to have an impact. It seems much easier to have an effect on management practices, sales and (short term) profits than on employment. Many interventions seem to lead to changes at the intensive margin, but fail to deliver productivity increases that go hand in hand with more jobs. This is coherent with the findings by Cho and Honorati (2014). Their meta-analysis of finance and training programs shows that in particular vocational and business training programs have positive effects on business outcomes such as improved knowledge and practice and sometimes income, but effects on a general set of labor market activities are generally quite weak and very often insignificant.

Yet, our review also revealed that about a third of the interventions covered by this review are not primarily designed to create employment but rather strive for income stabilization and poverty reduction. Hence, one should not expect massive impacts on job creation if interventions were not even intended to deliver this result. It also seems easier to create new businesses than to expand existing firms. Obviously, it is also far from certain, whether these new firms survive in the longer term. Most of the studies included do not provide an answer to this question, as their follow-up period is relatively short. Targeting seems to be key to achieve positive employment effects. Furthermore, not all potential and actual entrepreneurs can make good use of support. Different types of interventions will be required to increase employment for different groups. Interventions also need to pay attention to the interaction between different binding constraints. For instance, just improving business skills 
without facilitating access to capital (and vice versa), is often not enough to have an effect on investment and employment.

The review also shows that the available evidence is still sketchy in particular for large parts of SubSaharan Africa and Asia, regions in which, in the coming decades, the need for jobs is the highest. Findings from Latin-America, which dominate in this review, cannot necessarily be generalized and applied to other regions. Also only very few studies are able to assess the longer term effects of their interventions and policies and many studies fail to provide a detailed analysis of why certain effects occurred or did not occur - making it hard to extrapolate lessons. Moreover, it is also hard to tell from the results whether new jobs were created or whether workers were just tracked away from other activities. Furthermore, almost none of the 54 studies provided a detailed cost effectiveness analysis, i.e. how much does it cost to create an additional job with a certain program compared to another? This gap should alert both implementers and researchers. Implementers should provide the necessary numbers and researchers should go beyond the estimate of simple impacts, which is not really helpful for those who have to allocate resources across different interventions.

Many of the studies covered are based on RCTs, whereas others use a quasi-experimental design such as difference-in-difference estimation, propensity score matching techniques, regression discontinuity designs or several of these in combination. A striking finding of our review is that the study design matters for the impacts found. RCTs, which are typically seen as the 'gold standard', find less often positive employment effects than other methods, controlling for the type of intervention, type of country and type of firm that is targeted. This may suggest that in many of the studies that are based on a weaker identification strategy, selection bias is still an issue. However, it can also not be ignored that many RCTs have low statistical power due to small sample sizes and that they are applied particularly to small programs, very poor areas and very specific target groups. Under these conditions the generation of employment might be particularly difficult; hence these findings cannot necessarily be generalized. Finally, the results from RCTs might also be biased due to Hawthorne and John Henry effects, attrition and spill-overs, although many RCTs address the potential for such biases quite carefully.

Finally it is important to note that the methodology of a systematic review, because of its focus on rigorous evidence, must systematically ignore untargeted policies, such as financial sector development, large-scale infrastructure projects, trade policies and alike, which may be particularly beneficial for SMEs. Other approaches must be applied to find out how effective these interventions are in creating employment. This will of course imply to rely on less rigorous methods and hence the reliability of the findings need to be assessed very carefully in each case, but ignoring that literature may paint an overly pessimistic picture with respect to the potential of such policies and interventions to create jobs.

\section{Appendix}

\section{Appendix A: Search strategy}

\section{Electronic databases}

RePEc (Research Papers in Economics) / IDEAS (IDEAS uses the RePEc database); SSRN; EconLit; Labordoc (ILO); 3ie's database of policy briefs, systematic reviews and impact evaluations; Innovations for Poverty Action Publication Database; JPAL Evaluation Database; JPAL Publication Database; ILO Youth Employment Inventory; Research for Development; Web of Science.

Following the inclusion criteria, as specified above, we defined different sets of search terms which we combined using the Boolean operator 'AND' for the searches in electronic databases. In a first step, we combined search sets referring to the population, outcome and type of study, since the outcome is of main interest in this systematic review. However, in order to avoid missing potentially relevant studies by not searching sets for the interventions considered in this review, we conducted a second search that focused on the intervention categories set out in section 3, combining search sets for population, intervention and type of study. See Grimm and Paffhausen (2014) for the specific search terms used and results of the search. 


\section{Websites screened}

AFD (Agence Francaise de Developpement); African Development Bank; Asian Development Bank; AusAid (Australian Agency for International Development); CIDA (Canadian International Development Agency); DFID (Department for International Development); GDI (German Development Institute); GIZ (Deutsche Gesellschaft für Internationale Zusammenarbeit); IADB (InterAmerican Development Bank); IDS (Institute for Development Studies); IFC (International Finance Corporation); ILO (International Labor Organization); KfW Development Bank; ODI (Overseas Development Institute (ODI); OECD (Organisation for Economic Co-operation and Development) Development Center; SIDA (Swedish International Development Cooperation Agency); The SME Initiative at Innovations for Poverty Action (IPA); UNDP (United Nations Development Program); USAID; World Bank Group.

\section{Hand-searches of key journals}

Agricultural Economics; American Economic Review; American Economic Journal: Applied Economics; American Journal of Agricultural Economics; Econometrica; Economic Development and Cultural Change; ESR Review (previously Journal of Microfinance); Journal of African Economies; Journal of Development Economics; Journal of Development Effectiveness; Journal of Development Studies; Journal of Labor Economics; Journal of Political Economy; Journal of Small Business Economics; Quarterly Journal of Economics; Review of Economic Studies; World Bank Economic Review; World Development.

\section{Literature snowballing}

For included studies, citation tracking was conducted (forward searching). Moreover, their references have been screened for further relevant studies (backward searching).

Furthermore, the bibliographies of the World Bank's World Development Report 2013 on jobs and the following completed reviews have been hand-searched for relevant studies: Cho and Honorati (2014); Cirera et al. (2011); Duvendack et al. (2011); Hagen-Zanker et al. (2011); McKenzie and Woodruff (2012); Nataraj et al. (2012); Stewart et al. (2012); Stewart et al. (2010).

\section{Ongoing studies:}

For ongoing studies we heard of, we decided on inclusion, i.e. if they were relevant or marginally relevant, based on their title, and, if available, their statement of objectives. We then contacted the authors in order to check whether the results were already available for inclusion into the systematic review. 


\section{Appendix B: Overview of included studies}

\begin{tabular}{|c|c|c|c|c|c|c|c|c|}
\hline Ref. & Intervention & $\begin{array}{c}\text { Job } \\
\text { priority }\end{array}$ & Country & $\begin{array}{l}\text { Size of Enterprises } \\
\text { Targeted }\end{array}$ & $\begin{array}{l}\text { Women } \\
\text { targeted }\end{array}$ & Study Design & Length of follow-up & Program effect(s) \\
\hline \multicolumn{9}{|c|}{ Access to finance interventions } \\
\hline $\begin{array}{l}\text { Angelucci et al. } \\
\text { (2013) }\end{array}$ & $\begin{array}{l}\text { Microcredit, joint-liability, stand-alone, targeted at women that have a } \\
\text { business or self-employment activity or intend to start one. }\end{array}$ & yes & $\begin{array}{l}\text { Mexico (urban, peri- } \\
\text { urban, and rural) }\end{array}$ & Micro & yes & RCT & $\begin{array}{l}\text { up to three years; on } \\
\text { average } 26 \text { months }\end{array}$ & $\begin{array}{l}\text { BC: insignificant } \\
\text { E: insignificant }\end{array}$ \\
\hline $\begin{array}{l}\text { Arraíz et al. } \\
(2012)\end{array}$ & $\begin{array}{l}\text { Government-backed partial credit guarantees for Colombian MSMEs } \\
\text { without enough collateral, stand-alone. }\end{array}$ & yes & Colombia (national) & Small and medium & no & $\begin{array}{l}\text { Quasi- } \\
\text { experimental: } \\
\text { PSM + DID }\end{array}$ & up to two years & $\begin{array}{l}\text { E - current yr: } \\
\text { positive } \\
\text { E - } 1 \text { yr after: } \\
\text { positive } \\
\text { E - } 2 \text { yrs after: } \\
\text { positive }\end{array}$ \\
\hline $\begin{array}{l}\text { Attanasio et al. } \\
\text { (2011) }\end{array}$ & $\begin{array}{l}\text { Small loans; two different treatments: group-lending and individual } \\
\text { loans, stand-alone. } \\
\text { Target group: Relatively poor women in rural areas }\end{array}$ & yes & Mongolia (rural) & Micro & yes & RCT & 1.5 years & $\begin{array}{l}\text { BC - indiv. } \\
\text { lending: } \\
\text { insignificant } \\
\text { BC - group } \\
\text { lending: } \\
\text { insignificant } \\
\text { female BC - } \\
\text { indiv. lending: } \\
\text { insignificant } \\
\text { female BC - } \\
\text { group lending: } \\
\text { positive }\end{array}$ \\
\hline $\begin{array}{l}\text { Augsburg et al. } \\
\text { (2012) }\end{array}$ & $\begin{array}{l}\text { Individual-liability micro-credit to 'marginal' borrowers, i.e. loan } \\
\text { applicants who would otherwise be excluded from loans because of a } \\
\text { lack of collateral., stand-alone. }\end{array}$ & yes & $\begin{array}{l}\text { Bosnia and } \\
\text { Herzegovina (national) }\end{array}$ & Micro & no & RCT & 14 months & BC: positive \\
\hline $\begin{array}{l}\text { Banerjee et al. } \\
\text { (2011) }\end{array}$ & $\begin{array}{l}\text { Direct transfer of productive assets combined with provision of training } \\
\text { (inoculation of savings habits and integration into microfinance groups) } \\
\text { to the 'ultra poor', particularly women. }\end{array}$ & no & $\begin{array}{l}\text { India (rural West- } \\
\text { Bengal) }\end{array}$ & Micro & yes & RCT & 18 months & BC: insignificant \\
\hline $\begin{array}{l}\text { Banerjee et al. } \\
\text { (2013) }\end{array}$ & $\begin{array}{l}\text { Group-liability microcredit loans ranging between } \$ 200 \text { at market } \\
\text { exchange rates (or } \$ 1,000 \text { at PPP-adjusted exchange rates) } \$ 400 \text {, stand- } \\
\text { alone and targeted to women and the poor, but not the very poor. }\end{array}$ & no & India (Hyderabad) & Micro & yes & RCT & 3 to 3.5 years & $\begin{array}{l}\text { E -short term: } \\
\text { insignificant } \\
\text { E - long term: } \\
\text { insignificant } \\
\text { BC - short term: } \\
\text { insignificant } \\
\text { BC - long term: } \\
\text { insignificant }\end{array}$ \\
\hline
\end{tabular}


Barnes (2001) Group-liability microcredit, accompanied by an orientation session that teaches sound business management practices, and loan officers provide

Blattman et al. Nearly unconditional, unsupervised group cash transfers to pay for vocational training, tools, and business start-up costs, stand-alone, targeted at the poor and underemployed youth.

Bruhn and Love Opening of Banco Azteca in pre-existing stores for electronics and

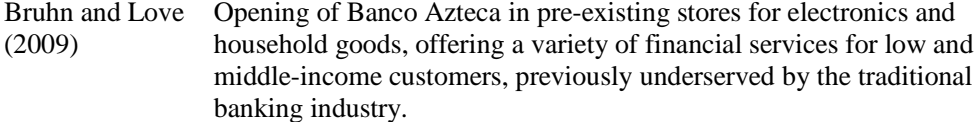

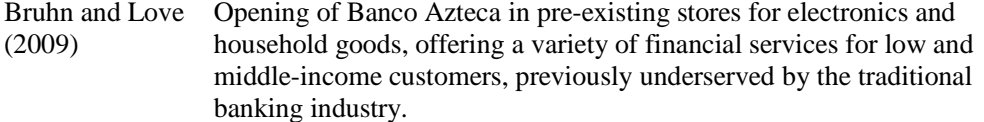

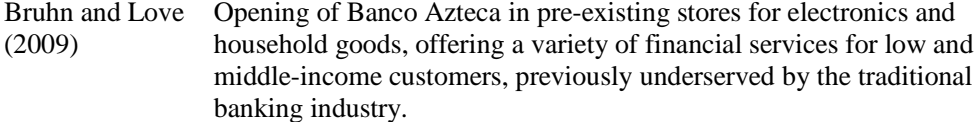

Microcredit, joint-liability, as well as individual-liability targeted at

existing enterprises.

Crepón et al.

(2011)

Da Silva et al. Constitutional financing funds, stand-alone

(2006)

Target group: firms in the northeastern region of Brazil, in particular SMEs

De Mel et al. Three different interventions: (1) a subsidized savings program, (2) emporary wage subsidies to incentivize hiring additional employees, and (3) a five-day training program based on the ILO's Improve Your Business (IYB) program, provided jointly (combination of two of these interventions) as well as stand-alone to male-owned enterprises with

two or fewer paid employees.

DeNegri et al. Public credit lines, stand-alone.

(2011)

\section{Eshetu et al. Joint intervention: enabling legal framework and streamlining regulatory conditions as well as specific support services (financial and business development services including a credit and saving scheme trainings, technology transfer, counseling, provision of working premises etc.}

Eslava et al. Public credit lines, stand-alone

(2012)

Field et al.

(2011)

Introduction of a grace period of two months for the initiation of the repayment of microloans. Normally repayments start after two weeks.
Zimbabwe (urban)

Uganda (Northern

Micro

Matching$$
\text { Region) }
$$

RCT

2 years

E - males:

significant

E - females:

negative

Mexico (national)

Micro

Quasiexperimenta:

up to 9 quarters

BC: positive

$$
\text { DID }
$$

Morocco (rural/semi-

Micro

urban)

Brazil (North/NorthEast)

Small and medium

RCT

Quasiexperiment

Sri Lanka (urban)

Micro

- program 1

positive

positive

$\mathrm{E}-\mathrm{F}+\mathrm{T}$ :

insignificant

E-F+WS:

positive

\section{Quasi-}

$$
\begin{aligned}
& \text { medium } \\
& \text { mestly small and }
\end{aligned}
$$

no experimental:

DID

Ethiopia (urban Dire

Micro

Dawa)

Quasiexperimental:

PSM

QuasiDID and PSM

India (Kolkata)

Micro
RCT up to 5 years

E - short term

positive

E - long term:

positive

up to 6 years

E: positive up to 4 years

E: positive 
Gubert and Individual-liability loans averaging $€ 500$ for urban microbusinesses and no Roubaud (2011) longer-term loans (from 24 to 36 months) to small and medium-sized

Kaboski and Village-level (micro-finance) institutions: (1) Production micro credit Townsend $\quad$ groups; (2) Rice bank; (3) Women’s group; (4) Buffalo banks.

(2005)

Karlan et al. Two types of interventions: (1) specific management consulting (2012) services and (2) unconditional cash grant of approximately US \$133Provided stand-alone as well as jointly to tailors and seamstresses.

Karlan and Individual liability microcredit, loans ranging from 5,000 to 25,000

Zinman (2011) pesos for existing enterprises, stand-alone.

Kondo et al. Group-liability microcredit, stand-alone.

(2008)

Macours et al. CCT complemented either by vocational training or a productive

(2012) investment grant targeted at rural households.

Nelson (2011) Large-scale, publicly-funded microfinance initiative which helped to set-up and to support independent village banks.

Resende (2012) Constitutional Financing Funds: Loans at subsidized interest rates,

Tan (2009) enterprises (SMEs) averaging $€ 8,000$ euros.
Madagascar (urban)

Micro

Micro

Thailand (rural/semiurban North-East and Central)

Ghana (urban)

Philippines (two

region)

Philippines (national)

Nicaragua (rural)

Thailand (rural/semiurban North-East and Central)

Micro

Micro

Micro

\section{Micro}

Quasixperimental:

up to 4 years

E: insignificant

Quasi-

experimental: IV

unclear

BC: insignificant

no

RCT

up to 11 months after the consulting stopped and 14 months after the capital drops

11-22months

\section{Engerive}

no

RCT

no

Quasiexperimenta:

DID

RCT

Micro and small

no

Quasiexperimental: IV

Quasi-

experimenta:

Matching

Seven different matching grants
open-ended, residual programs.
Chile (national)

yes

Small and medium
Quasi-

experimental: DID + PSM
3 to 5 years

BC: positive

E: positive

2 years

BC: positive

up to 6 years

BC - low wealth:

negative

BC - middle

wealth: positive $\mathrm{BC}$ - high wealth: insignificant

up to 6 years

E - 3yr period:

positive

E - 6yr period:

positive

up to 10 years

E - techn.

Assistanc

(BDS):

insignificant

E - cluster

formation (BDS):

insignificant

E - technology

dev. (BDS):

insignificant

E -any BDS:

positive 


\begin{tabular}{|c|c|c|c|c|c|c|c|c|}
\hline $\begin{array}{l}\text { Tarozzi et al. } \\
\text { (2013) }\end{array}$ & Joint-liability microcredit, combined with family planning program & yes & Ethiopia (rural) & Micro & no & RCT & up to 2 years & $\begin{array}{l}\text { BC - Oromiya: } \\
\text { insignificant } \\
\text { BC - Amhara: } \\
\text { insignificant }\end{array}$ \\
\hline
\end{tabular}

\section{Entrepreneurship training}

\begin{tabular}{|c|c|c|c|c|c|c|c|c|}
\hline $\begin{array}{l}\text { Bah et al. } \\
\text { (2011) }\end{array}$ & Financial and/or technical assistance analyzed jointly. & yes & Macedonia (national) & $\begin{array}{l}\text { Mostly micro and } \\
\text { small }\end{array}$ & no & $\begin{array}{l}\text { Quasi- } \\
\text { experimental: } \\
\text { matching }\end{array}$ & up to 3 years & $\begin{array}{l}\mathrm{E}-1^{\text {st }} \text { yr: positive } \\
\mathrm{E}-2^{\text {nd }} \text { yr: } \\
\text { positive } \\
\mathrm{E}-3^{\text {rd }} \text { yr: } \\
\text { positive }\end{array}$ \\
\hline $\begin{array}{l}\text { Bandiera et al. } \\
\text { (2012) }\end{array}$ & $\begin{array}{l}\text { Joint intervention that simultaneously provides: (1) vocational training } \\
\text { to run/start small-scale enterprises; and ( } 2 \text { ) information on health and } \\
\text { risky behaviors. Courses are supplemented by financial literacy courses } \\
\text { and targeted at adolescent girls aged 14-20. }\end{array}$ & yes & $\begin{array}{l}\text { Uganda (rural, urban } \\
\text { and semi-urban) }\end{array}$ & $\begin{array}{l}\text { Micro; target group } \\
\text { not necessarily } \\
\text { existing } \\
\text { entrepreneurs }\end{array}$ & yes & RCT & 2 years & BC: positive \\
\hline $\begin{array}{l}\text { Banerjee et al. } \\
\text { (2011) }\end{array}$ & $\begin{array}{l}\text { Direct transfer of productive assets combined with provision of training } \\
\text { (inoculation of savings habits and integration into microfinance groups) } \\
\text { to the 'ultra poor', particularly women. }\end{array}$ & no & $\begin{array}{l}\text { India (rural West- } \\
\text { Bengal) }\end{array}$ & $\begin{array}{l}\text { Micro; target group } \\
\text { not necessarily } \\
\text { existing } \\
\text { entrepreneurs }\end{array}$ & yes & RCT & 18 months & BC: insignificant \\
\hline $\begin{array}{l}\text { Bruhn and Zia } \\
\text { (2011) }\end{array}$ & $\begin{array}{l}\text { Three-day business and financial education training for microcredit } \\
\text { clients. }\end{array}$ & yes & $\begin{array}{l}\text { Bosnia and } \\
\text { Herzegovina (urban) }\end{array}$ & Micro & no & RCT & 6 months & $\begin{array}{l}\text { E: insignificant } \\
\text { BC: insignificant }\end{array}$ \\
\hline $\begin{array}{l}\text { Bruhn et al. } \\
\text { (2013) }\end{array}$ & $\begin{array}{l}\text { Subsidized consulting and mentoring services for owners/managers of } \\
\text { formal businesses. Consultants were asked to (1) diagnose the problems } \\
\text { that prevented the enterprises from growing, (2) suggest solutions and } \\
\text { (3) assist in implementing the solutions. }\end{array}$ & no & Mexico (Puebla) & $\begin{array}{l}\text { Mostly micro and } \\
\text { small }\end{array}$ & no & RCT & $\begin{array}{l}\text { up to one year (short } \\
\text { term) and between } \\
\text { 1-3 years (long } \\
\text { term) }\end{array}$ & $\begin{array}{l}\text { E - short term: } \\
\text { insignificant } \\
\text { E - long term: } \\
\text { positive }\end{array}$ \\
\hline $\begin{array}{l}\text { Calderon et al. } \\
\text { (2013) }\end{array}$ & $\begin{array}{l}\text { Stand-alone basic business training provided at no cost, focusing on the } \\
\text { application of the concept discussed in class on the participants' } \\
\text { businesses. Target group: small, female headed firms in the retail and } \\
\text { production sector }\end{array}$ & no & Mexico (rural) & Micro & yes & RCT & $\begin{array}{l}\text { up to } 1 \text { year (short } \\
\text { term effects) and } \\
\text { about } 2.5 \text { years } \\
\text { (medium term } \\
\text { effects) }\end{array}$ & $\begin{array}{l}\text { E - below median } \\
\text { profit: } \\
\text { insignificant } \\
\text { E - above median } \\
\text { profit: } \\
\text { insignificant }\end{array}$ \\
\hline $\begin{array}{l}\text { Cho et al. } \\
\text { (2012) }\end{array}$ & $\begin{array}{l}\text { Vocational training apprenticeship combined with entrepreneurial } \\
\text { support and life skills training and, in some cases, start-up capital. } \\
\text { Target group: vulnerable youth who are poor, orphaned, HIV/AIDS } \\
\text { vulnerable, school dropouts. }\end{array}$ & yes & Malawi (national) & $\begin{array}{l}\text { Micro; target group } \\
\text { not necessarily } \\
\text { existing } \\
\text { entrepreneurs }\end{array}$ & no & RCT & 4 months & BC: insignificant \\
\hline
\end{tabular}


De Mel (2013b) Three different interventions: (1) a subsidized savings program, (2) temporary wage subsidies to incentivize hiring additional employees, and (3) a five-day training program based on the ILO's Improve Your Business (IYB) program, provided jointly (combination of two of these interventions) as well as stand-alone to male-owned enterprises with 2 or fewer paid employees.

'ILO's 'Start-and-Improve Your Business program“ provided to female

current as well as potentia Your Business progrc

Drexler et al. Two different stand-alone training interventions: (1) Standard

(2013) accounting training, and (2) rule-of-thumb training, which taught

accounting training, and (2) rule-of-thumb training, which taught

microentrepreneurs interested in training.

Galasso et al. Vouchers that entitled to hire an employee at a subsidized wage for 18

months. In a variant of that intervention employees received special

skill training.

Giné and Hands-on business training based on the ILO's 'Know About Business'

Mansuri (2011) modules was added to microfinance. In addition, one-on-one follow-up

training sessions and beneficiaries had the opportunity to participate in a

lottery for a loan up to seven times the average loan size.

Two different programs providing training and finance to low-

Peru (urban)

income/poor youth (18-25 years) either already owning a

microenterprise or interested in establishing one. Focus was on business

plan development.

Karlan and

Training is added to microcredit program. The training included general yes

Valdivia (2011) business skills and strategy training, not client-specific problem solving.

Target group: female microentrepreneurs who are microcredit clients.

Klinger and Multi-phased business plan competition

Schündeln

(2011)
Sri Lanka (urban)

Micro

RCT

$\mathrm{E}-\mathrm{T}$

$\mathrm{E}-\mathrm{T}+\mathrm{F}$

insignificant

E-T+WS:

positive

Sri Lanka (urban)

Micro

yes

RCT

2 years

$\mathrm{BC}-\mathrm{T}$ - short term: positive $\mathrm{BC}-\mathrm{T}$ - long term: insignificant $\mathrm{BC}-\mathrm{T}+\mathrm{F}-\mathrm{short}$ term: positive $\mathrm{BC}-\mathrm{T}+\mathrm{F}$ - long term: insignificant

Dominican Republic

Mostly micro

no

RCT

1 to 2 years

E: insignificant

Argentina (urban)

Micro

no

18 months

BC: positive

Pakistan (rural)

no
Micro

18 months after

training and 6 months after loan

lottery

Micro; no necessarily existing entrepreneurs

no Quasiexperimental:

PSM

3 months (CID

program) and 11 program)

Peru (regional)

Micro

yes

RCT

up to 2 years

E: insignificant
BC: insignificant

Micro and small;

El Salvador,

Guatemala and

not necessarily

no

Quasi-

1 to 3 years

BC: positive existing
$\mathrm{BC}$ - beneficiary

involved:

insignificant

insignificant

E - CID: positive

BC - JUMP:

positive

country distribution 
Lopez-Acevedo Subsidies for SMEs to (1) hire independent instructors to design and and Tinajerodeliver training, and (2) to reduce the costs of producing training

Bravo (2010) materials, developing training programs, and assessing workers' skills based on labor competency standards.

Macours et al. CCT complemented either by vocational training or a productive

(2012) investment grant.

Target group: Rural households

Premand et al. Introduction of an innovative entrepreneurship track in the university (2012) curriculum, including entrepreneurship courses, external private sector coaching delivered by entrepreneurs, and business plan development. Target group: University students.

Steiner et al. Stand-alone business training program promoting productive activities (2010) in the agricultural sector; and agro-industrial sector, as well as in services and industry and targeted at the unemployed youth (16-25) in services and industry and and remote areas.

Valdivia (2011) Stand-alone training (general and individualized). There were two different treatments: (1) Regular business training consisting of persona development, business development and management and productivity improvements; and (2) Additional individualized support in the form of technical assistance (TA) Target group: Female microentrepreneurs in Lima.

unclear)

Tunisia (national)

Colombia (rural)

Peru (urban)
Mostly medium size

Micro; not necessarily existing entrepreneurs

\section{Micro; not} necessarily existing

entrepreneurs

Micro; not necessarily existing entrepreneurs

Quas PSM and DID

Micro

\section{Business development services (BDS)}

\begin{tabular}{|c|c|c|c|c|c|c|c|c|}
\hline $\begin{array}{l}\text { Arráiz et al. } \\
\text { (2013) }\end{array}$ & $\begin{array}{l}\text { Supplier development program providing public subsidies for projects } \\
\text { aimed at strengthening the management of SMEs that supply large } \\
\text { firms. Each project must include between } 10 \text { to } 20 \text { SMEs. }\end{array}$ & no & Chile (national) & SMEs & no & $\begin{array}{l}\text { Quasi- } \\
\text { experimental: } \\
\text { PSM }\end{array}$ & up to three years & E: positive \\
\hline $\begin{array}{l}\text { Benavente } \\
\text { (2007) }\end{array}$ & $\begin{array}{l}\text { Technology development fund providing matching-grants for projects } \\
\text { aimed at developing new products and improving production processes. } \\
\text { Covers the development of prototypes and market testing. }\end{array}$ & yes & Chile (national) & SMEs & no & $\begin{array}{l}\text { Quasi- } \\
\text { experimental: } \\
\text { PSM+DID }\end{array}$ & unclear & E: positive \\
\hline $\begin{array}{l}\text { Castillo et al. } \\
\text { (2011) }\end{array}$ & Co-financing (up to 50\%) for product innovation or process innovation. & no & Argentina (national) & SMEs & no & $\begin{array}{l}\text { Quasi- } \\
\text { experimental: } \\
\text { PSM + DID }\end{array}$ & up to 8 years & $\begin{array}{l}\text { E - product } \\
\text { innovation: } \\
\text { positive } \\
\text { E - process } \\
\text { innovation: }\end{array}$ \\
\hline
\end{tabular}


$\begin{array}{ll}\text { Eshetu et al. } & \text { Joint intervention: enabling legal framework and streamlining } \\ \text { (2013) } & \text { regulatory conditions as well as specific support services (financial and } \\ \text { business development services including a credit and saving scheme } \\ \text { trainings, technology transfer, counseling, provision of working } \\ \text { premises etc.). }\end{array}$

Lopez-Acevedo

and Tinajero-

Four different programs including: (1) tax breaks, (2) finance audits and yes support for investments to reduce environmental risks, (3) fiscal

incentives for technological innovation, and (4) a training of the

industrial workforce.

Tan (2009)

Seven different matching grants and credit programs, and two other,

open-ended, residual programs. yes yes

Ethiop

Dawa)

Mexico (national)
Quasi-

experimental:

PSM

Quasi-

experimental:

PSM

up to 6 years

E: positive

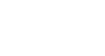

up to 5 years positive

audit: nega

- fiscal
Most

sized no

Quasi-

experimental:

DID+PSM
E - tax breaks:

$\mathrm{E}$ - environmen

incentives and

techn. innovation:

positive

E - other state

support:

insignificant

E - any program:

positive

E - techn.

assistance (BDS):

insignificant

E - cluster

formation (BDS):

insignificant

$\mathrm{E}$ - technology

dev. (BDS):

insignifciant

E-any BDS:

positive

\section{Wage incentives}

Alatas and Introduction of a minimum wage legislation (province-specific wage

Cameron (2010) levels).

Betcherman et

al. (2010)
Social security contribution and wage subsidies as well as land and electricity subsidies (the latter for particular cases). yes Turkey (national)

Turkey (national)
Small and medium sized formal firms
Small and medium

sized formal firms no

(n)

$\begin{array}{ll}\text { Quasi- } & \text { Average exposure } \\ \text { experimental: } & \text { time not reported } \\ \text { Matching + DID } & \\ & \end{array}$

\section{experimental:}

no

Quasi-

experimental:
E - small firms:

negative

- domestic firms: positive

$\mathrm{E}$ - large foreign firms: positive

E: positive 
De Mel et al. Three different interventions: (1) a subsidized savings program, (2) temporary wage subsidies to incentivize hiring additional employees, and (3) a five-day training program based on the ILO's Improve Your Business (IYB) program, provided jointly (combination of two of these interventions) as well as stand-alone to male-owned enterprises with 2 or fewer paid employees.

Fretwell et al. On-the-job training, averaging 4.5 months in length. Contracts with training agencies and enterprises were 'performance-based' with prenegotiated job placement rates and trainees were provided with a token amount for living and travel expenses.

\section{Business environment: Interventions to promote formalization (BE)}

Bruhn (2011) Federal program targeted at municipalities that 'one-stop' firm registration offices allowing small firms to obtain a license to operate in two days or less and to postpone health and social security inspections for three months. The program reduced registration procedures from 30 to 2 days.

Courseuil and A tax incentives program that combines, simplifies and promotes the Moura (2011) collection of federal taxes from micro-firms and small companies, with collection of federal taxes from micro-firms and small companies, with
lower, though progressive, tax rates on the same base for calculation (gross revenue). The program combines reductions both in monetary and administrative costs of tax payment.

de Mel et al. Information about procedures and costs and benefits of formalization, (2013a) provided either alone or with capital.

Fajnzylber et al. Simplified tax system for micro-firms, including also an overall

(2011) - reduction of taxes of up to $8 \%$.

Kaplan et al. Federal program targeted at municipalities that 'one-stop' firm

registration offices allowing small firms to obtain a license to operate in

two days or less and to postpone health and social security inspections

for three months. The program reduced registration procedures from 30 to 2 days.
Mexico (national)

expratan

exp

Quasi-

DID

up to 4 years

BC: positive yes

Brazil (national)

Mostly medium sized

no

Quasiexperimental:

RDD

Micro

Quasixperimental: RDD, IV and

$$
\text { DID }
$$

up to 1 year

E - all microfirms: positive E - firms with least one employee: positive

\section{E: positive}

Source: Own representation. 


\section{References}

References of studies that have been systematically reviewed

Alatas, V. and L. A. Cameron (2008), 'The impact of Minimum Wages on Employment in a LowIncome Country: A Quasi-Natural Experiment in Indonesia', Industrial and Labor Relations Review, Vol. 61(2), pages 201-223.

Angelucci, M., D. Karlan and J. Zinman (2013), 'Win Some Lose Some? Evidence from a Randomized Microcredit Program Placement Experiment by Compartamos Banco', IZA Discussion Paper Series, No. 7439, IZA.

Arráiz, I., F. Henríquez and R. Stucchi (2013), 'Supplier development programs and firm performance: evidence from Chile’, Small Business Economics, Vol. 41, pages 277-293.

Arraíz, I., M. Meléndez and R. Stucchi (2012), 'Partial Credit Guarantees and Firm Performance: Evidence from the Colombian National Guarantee Fund', OVE Working Paper, No. 02/2012, Office of Evaluation and Oversight (OVE), Inter-American Development Bank.

Attanasio, O., B. Augsburg, R. De Haas, E. Fitzimons and H. Harmgart (2011), 'Group lending or individual lending? Evidence from a randomised field experiment in Mongolia', IFS Working Paper, No. 11/20, Institute for Fiscal Studies.

Augsburg, B., R. De Haas, H. Heimgart and C. Meghir (2012), 'Microfinance at the margin: experimental evidence from Bosnia and Herzegovina', EBRD Working Paper, No. 146, European Bank of Reconstruction and Development.

Bah, E. H., J. C. Brada and T. Yigit (2011), 'With a little help from our friends: the effect of USAID assistance on SME growth in a transition economy', Journal of Comparative Economics, Vol. 39, pages 205-220.

Bandiera, O., N. Buehren, R. Burgess, M. Goldstein, S. Gulesci, I. Rasul and M. Sulaiman (2012), 'Empowering adolescent girls: Evidence from a randomized control trial in Uganda', Mimeo, London School of Economics.

Banerjee, A., E. Duflo, R. Chattopadhyay and J. Shapiro (2011), 'Targeting the Hard-Core Poor: An Impact Assessment', Mimeo, Poverty Action Lab, MIT.

Banerjee, A., E. Duflo, R. Glennerster and C. Kinnan (2013), 'The miracle of microfinance? Evidence from a randomized evaluation', Mimeo, Poverty Action Lab, MIT.

Barnes, C. (2001), 'Microfinance Program Clients and Impact: An assessment of Zambuko Trust, Zimbabwe', Assessing the Impact of Microenterprise Services, Report, United States Agency for International Development.

Benavente, J.M., G. Crespi and A. Maffioli (2007), 'Public support to firm-level innovation: an evaluation of the FONTEC program', OVE Working Paper, No. 05/2007, Office of Evaluation and Oversight (OVE), Inter-American Development Bank.

Betcherman, G., N. Meltem Daysal and C. Pagés (2010), 'Do employment subsidies work? Evidence from regionally targeted subsidies in Turkey’, Labor Economics, Vol. 17, pages 710-722.

Blattman, C., N. Fiala and S. Martinez (2012), 'Employment Generation in Rural Africa - Mid-Term Results from an Experimental Evaluation of the Youth Opportunities Program in Northern Uganda', DIW Discussion Papers, No. 1201, DIW.

Bruhn, M. and L. Inessa (2009), 'The Economic Impact of Banking the Unbanked. Evidence from Mexico’, World Bank Policy Research Working Paper, No. 4981, World Bank.

Bruhn, M. and B. Zia (2011), 'Stimulating Managerial Capital in Emerging Markets. The Impact of Business and Financial Literacy for Young Entrepreneurs', World Bank Policy Research Working Paper, No. 5642, World Bank.

Bruhn, M. (2011), 'License to sell: the effect of Business Registration Reform on Entrepreneurial Activity in Mexico’, Review of Economics and Statistics, Vol. 93(1), pages 283-286. 
Bruhn, M., D. Karlan and A. Schoar (2013), 'The Impact of Consulting Services on Small and Medium Enterprises: Evidence from a Randomized Trial in Mexico’, World Bank Policy Research Working Paper, No. 6508, World Bank.

Calderon, G., J. M. Cunha and G. de Giorgi (2013), 'Business Literacy and Development: Evidence from a Randomized Controlled Trial in Rural Mexico’, Mimeo, Stanford University.

Castillo, V., A. Maffioli, S. Rojo and R. Stucci (2011), 'Innovation Policy and Employment', IADB Working Paper, No. IDB-TN-341, Inter-American Development Bank.

Cho, Y., D. Kalomba, M. Mobarak and V. Orozco (2012), 'The effects of apprenticeship training for vulnerable youth in Malawi', Mimeo, World Bank.

Courseuil, C. H. and R. L. de Moura (2011), 'The Effects Of Tax Incentives For Small Firms On Employment Levels’, FGV Working Paper series ‘Ensaios Econômicos’, No. 701, FGV/EPGE Escola Brasileira de Economia e Finanças, Getulio Vargas Foundation, Brazil.

Crepón, B., F. Devoto, E. Duflo and W. Pariente (2011), 'Impact of microcredit in rural areas of Morocco: Evidence from a Randomized Evaluation’, MIT Working Paper, No. 6659, MIT.

Da Silva, A. M. A., G. Mendes Resende, S. da Mota and R. Neto (2006), 'Avaliação Econômica dos fundos constiucionais de financiamento do Nordeste e do Norte (FNE e FNO)', Discussion Paper, No. 1207, Instituto de Pesquisa Economica Aplicada (IPEA), Brazil.

De Mel, S., D. McKenzie and C. Woodruff (2012), 'Business training and female enterprise start-up, growth, and dynamics: Experimental evidence from Sri Lanka’, World Bank Policy Research Working Paper, No. 6145, World Bank.

De Mel, S., D. McKenzie and C. Woodruff (2013a), 'The Demand for, and Consequences of, Formalization among Informal Firms in Sri Lanka', American Economic Journal: Applied Economics, Vol. 5 (2), pages 122-50.

De Mel, S., D. McKenzie and C. Woodruff (2013b), 'What generates Growth in Microenterprises? Experimental Evidence on Capital, Labour and Training', Mimeo, World Bank.

De Negri, J.A., A. Maffioli, C. M. Rodriguez and G. Vázquez (2011), 'The Impact of Public Credit Programs on Brazilian Firms’, Inter-American Development Bank Working Paper, No. IDB-WP-293, Inter-American Development Bank.

Drexler, A., G. Fischer and A. Schoar (2013): 'Keeping it Simple: Financial Literacy and Rules of Thumb’, CEPR Discussion Paper, No. DP7994, CEPR .

Eshetu, T., M. Ketema and H. Kassa (2013), 'Economic Impact of Support Service Program on Micro and Small Enterprises: The Case of Dire Dawa Administration, Ethiopia', Agris on-line Papers in Economics and Informatics, Vol. 5(1), pages 21-29.

Eslava, M., A. Maffioli and M. Meléndez (2012), 'Second-tier Government Banks and Firm Performance. Micro-Evidence from Colombia', IADB Working Paper, No. IDB-WP-294, InterAmerican Development Bank.

Fajnzylber, P. W., F. Maloney and Gabriel V. Montes-Rojas (2011), 'Does formality improve microfirm performance? Evidence from the Brazilian SIMPLES program', Journal of Development Economics, Vol. 94, pages 262-276.

Field, E., P. Rohini, J. Papp and N. Rigol (2011), 'Term Structure of Debt and Entrepreneurship: Experimental Evidence from Microfinance’, Mimeo, Harvard University.

Fretwell, D. H., J. Benus and C. J. O’Leary (1999), 'Evaluating the Impact of Active Labor Market Porgrams: Results of Cross Country Studies in Europe and Asia', Social Protection Discussion Paper Series, No. 9915, World Bank.

Galasso, E., M. Ravallion and A. Salvia (2004), 'Assisting the transition from workfare to work: A randomized experiment’, Industrial and Labor Relations Review, Vol. 58(1), pages 128-142. 
Giné, X. and G. Mansuri (2011), 'Money or ideas? A Field Experiment on Constraints to entrepreneurship in rural Pakistan’, Mimeo, World Bank.

Gubert, F. and F. Roubaud (2011), 'The impact of Microfinance Loans on Small Informal Enterprises in Madagascar. A panel data analysis', Social Protection Discussion Paper Series, No. 77931, World Bank.

Jaramillo, M. and S. Parodi (2003), ‘Jóvenes emprendedores’, Instituto Apoyo, Peru.

Kaboski, J. P. and R. M. Townsend (2005), 'Policies and impact: An analysis of village-level microfinance institutions', Journal of the European Economic Association, Vol. 3(1), pages 1-50.

Kaplan, D. S., E. Pedra and E. Seira (2011), 'Entry regulation and business start-ups: Evidence from Mexico’, Journal of Public Economics, Vol. 95, pages 1501-1515.

Karlan, D., R. Knight and C. Udry (2012), 'Hoping to Win, Expected to Lose: Theory and Lessons on Microenterprise Development’, CGD Working Paper, No. 312, Center for Global Development.

Karlan, D. and M. Valdivia (2011), 'Teaching Entrepreneurship: Impact of Business Training on Microfinance clients and Institutions', Review of Economics and Statistics, Vol. 93(2), pages 510-527.

Karlan, D. and J. Zinman (2011), 'Microcredit in Theory and Practice: Using Randomized Credit Scoring for Impact Evaluation’, Science, Vol. 332(1278).

Klinger, B. and M. Schündeln (2011), 'Can Entrepreneurial Activity be Taught? Quasi-Experimental Evidence from Central America’, World Development, Vol. 39(9), pages 1592-1610.

Kondo, T., A. Orbeta, Jr., C. Dingcong and C. Infantado (2008), 'Impact of microfinance on rural households in the Philippines', PIDS Discussion Paper Series, No. 05/2008, Philippine Institute for Development Studies.

Lopez-Acevedo, G. and M. Tinajero-Bravo (2010), 'Evaluating Enterprise support programs using panel firm data’, World Bank Policy Research Working Paper, No. 5186, World Bank.

Macours, K., P. Premand and R. Vakis (2012), 'Transfers, Diversification and Household Risk Strategies’, World Bank Policy Research Working Paper, No. 6053, World Bank.

Nelson, L. K. (2011), 'From Loans to Labor: Access to Credit, Entrepreneurship and Child Labor', Mimeo, University of California.

Premand, P., S. Brodmann, R. Almeida, R. Grun and M. Barouni (2012), 'Entrepreneurship training and self-employment among University Graduates: Evidence from a randomized trial in Tunisia', IZA Discussion Paper, No. 7079, IZA.

Resende, G. M. (2012), 'Measuring Micro- and Macro-Impacts of Regional Development Policies: the case of the Northeast Regional Fund (FNE) Industrial Loans in Brazil, 2000-2006', Regional Studies, No. 01/2012, pages 1-19.

Steiner, R., P. Acosta, N. Rojas, N. Millán, C. Castañeda and J. L. Gonzáles (2010), 'Evaluación de impacto del programa jóvenes rurales emprendedores del servicio nacional de aprendizaje - SENA', Unpublished Evaluation Report, FEDESARROLLO - Centro de Investigación Económica y Social, Colombia.

Tan, H. (2009), 'Evaluating SME Support Programs in Chile Using Panel Firm Data’, World Bank Policy Research Working Paper, No. 5082, World Bank.

Tarozzi, A., J. Desai, K. Johnson and (2013): 'On the Impact of Microcredit: Evidence from a Randomized Intervention in Rural Ethiopia’, BREAD Working Paper, No. 382, BREAD.

Valdivia, M. (2011), 'Training or Technical Assistance? A Field Experiment to Learn What Works to Increase Managerial Capital for Female Microentrepreneurs', CAF Working Papers, No. 02/2011, CAF - Banco de Desarrollo de América Latina, Venezuela. 


\section{Other References}

Andrade, G.H., M. Bruhn and D. McKenzie (2013), A Helping Hand of the Long Arm of the Law. Experimental Evidence on what Governments Can Do to Formalize Firms. World Bank Policy Research Working Paper, No. 6435, World Bank.

Ayyagari, M., A. Demirguc-Kunt and V. Maksimovic (2011), 'Small vs. Young Firms Across the World: Contribution to Employment, Job Creation, and Growth', World Bank Policy Research Working Paper, No. 5631, World Bank.

Betchermann, G. (2014), 'Labour Market Regulations: What do we know about their Impacts in Developing Countries?', forthcoming in World Bank Research Observer.

Betcherman, G., M. Godfrey, S. Puerto, F. Rother and A. Stavreska (2007), 'A review of interventions to support young workers: findings of the youth employment inventory', Social Protection Discussion Papers, No. 41412, World Bank.

Bruhn, M. and D. McKenzie (2013), Entry Regulation and Formalization of Microenterprises in Developing Countries, World Bank Policy Research Working Paper, No. 6507, World Bank.

Cho, Y. and M. Honorati (2014), 'Entrepreneurship programs around the Developing World: A Meta Analysis', forthcoming in Labour Economics.

Cirera, X., D. Willenbockel, and R. Lakshman (2011), 'What is the evidence of the impact of tariff reductions on employment and fiscal revenue in developing countries?', Technical Report, EPPICentre, Social Science Research Unit, Institute of Education, University of London.

Cirera, X., R. Lakshman (2013), 'The Impact of Export Processing Zones on Employment, Wages and Labour Conditions in Developing Countries’, 3ie Grantee Final Systematic Review.

De Mel, S., D. McKenzie and C. Woodruff (2009), 'Are Women more Credit Constrained? Experimental Evidence on Gender and Microenterprise Returns', American Economic Journal, Applied Economics, Vol. 1(3), pages 1-32.

De Mel, S., D. McKenzie and C. Woodruff (2010), 'Wage subsidies for Microenterprises', American Economic Review, Papers and Proceedings, Vol. 100, pages 614-619.

De Soto, H. (1989), 'The Other Path', Harper and Row, New York.

Duvendack, M., R. Palmer-Jones, J.G. Copestake, L. Hooper, Y. Loke and N. Rao (2011), 'What is the evidence of the impact of microfinance on the well-being of poor people?', EPPI-Centre, Social Science Research Unit, Institute of Education, University of London.

Fafchamps, M., D. McKenzie, S. R. Quinn and C. Woodruff (2011), 'When is capital enough to get female microenterprises growing? Evidence from a randomized experiment in Ghana', NBER Working Papers, No. 17207, NBER.

Grimm, M. and A. L. Paffhausen (2014), 'Interventions for employment creation in micro, small and medium-sized enterprises - A systematic review’, Mimeo, KfW Development Bank, Frankfurt.

Hagen-Zanker, J., A. McCord and R. Holmes (2011), 'The impact of employment guarantee schemes and cash transfers on the poor', Overseas Development Institute.

Kluve, J. (2010), 'The effectiveness of European active labor market programs'. Labour Economics, Vol. 17, pages 904-918.

Lipsey, M. W., D. B. Wilson (2001), 'Practical Meta-Analysis', Practical Meta Analysis. Applied Social Research Methods Series, Vol. 49.

Maloney, W.F. (2004), 'Informality Revisited', World Development, Vol. 32(7), pages 1159-1178.

McKenzie, D. (2010), Impact Assessments in Finance and Private Sector Development: What Have We Learned and What Should We Learn? World Bank Research Observer, Vol. 25 (2), pages 209233- 
McKenzie, D. and Y.S. Sakho (2010), Does it pay firms to register for taxes? The impact of formality on firm profitability. Journal of Development Economics, Vol. 91 (1), pages 15-24.

McKenzie, D. and C. Woodruff (2014), What are we learning from business training and entrepreneurship evaluations around the developing world?, World Bank Research Observer, Vol. 29 (1), pages 48-82.

Nataraj, S., F. Perez-Arce, S. Srinivasan, and K. Kumar (2012), 'The impact of labour market regulation on employment in Low-Income Countries: a systematic review', RAND Corporation.

Puerto, O. S. (2007), 'Labor Market Impact on Youth: A Meta-Analysis of the Youth Employment Inventory’, Mimeo, World Bank.

Stewart, R., C. van Rooyen and T. de Wet (2012), 'Do micro-credit, micro-savings and micro-leasing serve as effective financial inclusion interventions enabling poor people, and especially women, to engage in meaningful economic opportunities in LMICs?', EPPI-Centre, Social Science Research Unit, Institute of Education, University of London.

Stewart, R., C. van Rooyen, K. Dickson, M. Majoro, and T. de Wet (2010), 'What is the impact of microfinance on poor people? A systematic review of evidence from sub-Saharan Africa', EPPICentre, Social Science Research Unit, University of London.

Tripney, J., J. Hombrados, M. Newman, K. Hovish, C. Brown, K. Steinka-Fry, E. Wilkey (2013), 'Post-Basic Technical and Vocational Education and Training (TVET) Interventions to Improve Employability and Employment of TVET Graduates in Low- and Middle-Income Countries: A Systematic Review', Campbell Collaboration.

Vaessen, J., F. L. Leeuw, S. Bonilla, A. Rivas, R. Lukach, J. Bastiaensen and N. Holvoet (2012), 'The effect of microcredit on women's control over household spending in developing countries', Protocol, Campbell Collaboration.

Waddington, H. and J. G. Hombrados (2012), 'Tool to assess risk of bias and internal validity of social experiments and quasi-experiments', Mimeo, 3ie.

World Bank (2012), ‘World Development Report 2013: Jobs’, World Bank. 


\section{Tables and Figures}

Table 1: Regional distribution and basic characteristics of included studies

\begin{tabular}{|c|c|c|c|c|c|}
\hline & Finance & Training & BDS/Wage & Business E. & Total \\
\hline \multicolumn{6}{|l|}{ Region } \\
\hline Latin America \& Caribbean & 9 & 11 & 5 & 4 & 29 \\
\hline Sub-Saharan Africa & 6 & 2 & 1 & 0 & 9 \\
\hline South Asia & 4 & 4 & 1 & 1 & 10 \\
\hline East Asia \& Pacific & 5 & 0 & 1 & 0 & 6 \\
\hline Europe \& Central Asia & 1 & 2 & 2 & 0 & 5 \\
\hline Middle East \& North Africa & 1 & 1 & 0 & 0 & 2 \\
\hline \multicolumn{6}{|l|}{ Firm size } \\
\hline Micro & 20 & 17 & 2 & 2 & 41 \\
\hline Small & 3 & 2 & 2 & 2 & 9 \\
\hline Medium & 30 & 1 & 6 & 1 & 38 \\
\hline \multicolumn{6}{|l|}{ Stand-alone or joint } \\
\hline Stand-alone & 18 & 6 & 2 & 3 & 29 \\
\hline Joint & 6 & 12 & 7 & 2 & 27 \\
\hline Both & 2 & 2 & 1 & 0 & 5 \\
\hline \multicolumn{6}{|l|}{ Empl. creat. primary objective } \\
\hline Yes & 16 & 11 & 7 & 5 & 39 \\
\hline No & 10 & 9 & 3 & 0 & 22 \\
\hline Total (per intervention area) & 26 & 20 & 10 & 5 & 61 \\
\hline
\end{tabular}

Notes: The total count does not add up to 54 because some studies have been included in more than one category. Source: Own computations based on information made available by the evaluations. 
Table 2: Distribution of standardized effect sizes by intervention area

\begin{tabular}{|c|c|c|c|c|c|c|c|c|}
\hline & \multicolumn{2}{|c|}{ Finance } & \multicolumn{2}{|c|}{ Training } & \multicolumn{2}{|c|}{ BDS/Wage } & \multicolumn{2}{|c|}{ Business E. } \\
\hline & Count & Share $(\%)$ & Count & Share (\%) & Count & Share (\%) & Count & Share $(\%)$ \\
\hline Negative effect size $(<0)$ & 13 & 24.1 & 8 & 22.2 & 2 & 10.5 & 0 & 0 \\
\hline Small effect size $(>0,<0.2)$ & 33 & 61.1 & 16 & 44.4 & 12 & 57.9 & 5 & 71.4 \\
\hline Medium effect size $(>0.2,<0.5)$ & 7 & 13.0 & 5 & 13.9 & 2 & 10.5 & 0 & 0 \\
\hline Large effect size $(>0.5,<1)$ & 1 & 1.9 & 7 & 19.4 & 3 & 15.8 & 2 & 28.6 \\
\hline Total & 54 & 100 & 36 & 100 & 19 & 100 & 7 & 100 \\
\hline
\end{tabular}

Notes: Effect sizes are computed as the standardized mean difference (SMD), i.e. as the ratio between the change in the outcome due to the intervention divided by the standard deviation of the outcome in the control group (or at baseline). If the outcome is a binary outcome such as 'having set up a firm or not' the risk ratio is computed $(-1)$. In those studies where such impact measurements were not directly provided they were computed based on the available information. However, some studies do not provide all the necessary information, in these cases we based the estimate just on the reported $t$-values of the impact and the sample sizes of treatment and control groups using the formulas given in Lipsey and Wilson (2001). This implies that effect sizes are not fully comparable across studies and hence can only roughly reflect the order of magnitude of program impacts. For one intervention an effect size measure could not be computed.

Source: Own computations based on information made available by the evaluations. 
Table 3: Description of sample of impacts used for the meta-regression analysis

\begin{tabular}{|c|c|c|c|c|c|}
\hline $\begin{array}{l}\text { Variable } \\
\end{array}$ & Observations & Mean & Std. Dev. & Min & Max \\
\hline Positive significant program effect & 116 & 0.457 & 0.500 & 0 & 1 \\
\hline Effect size ${ }^{a}$ & 115 & 0.145 & 0.283 & -0.891 & 1.5 \\
\hline Training & 116 & 0.310 & 0.465 & 0 & 1 \\
\hline Finance & 116 & 0.466 & 0.501 & 0 & 1 \\
\hline BDS & 116 & 0.121 & 0.327 & 0 & 1 \\
\hline $\begin{array}{l}\text { Private sector incentives and } \\
\text { business environment }\end{array}$ & 116 & 0.103 & 0.306 & 0 & 1 \\
\hline Empl. creat. primary objective & 116 & 0.690 & 0.465 & 0 & 1 \\
\hline Joint intervention & 116 & 0.491 & 0.502 & 0 & 1 \\
\hline Intervention targets women & 116 & 0.198 & 0.400 & 0 & 1 \\
\hline Evaluation based on an RCT & 116 & 0.534 & 0.501 & 0 & 1 \\
\hline Microenterprises & 116 & 0.664 & 0.474 & 0 & 1 \\
\hline Small enterprises & 116 & 0.147 & 0.355 & 0 & 1 \\
\hline Medium enterprises & 116 & 0.190 & 0.394 & 0 & 1 \\
\hline LIC & 116 & 0.086 & 0.282 & 0 & 1 \\
\hline LMIC & 116 & 0.345 & 0.477 & 0 & 1 \\
\hline UMIC & 116 & 0.569 & 0.497 & 0 & 1 \\
\hline $\begin{array}{l}\text { Measured outcome is business } \\
\text { creation }\end{array}$ & 116 & 0.371 & 0.485 & 0 & 1 \\
\hline
\end{tabular}

Notes: ${ }^{\text {a) }}$ Regarding the computation of effect sizes, see Note to Table 2. For one intervention an effect size measure could not be computed. Source: Own representation. 
Table 4: Results from the meta-regression analysis

\begin{tabular}{|c|c|c|c|c|c|c|c|}
\hline & $\begin{array}{c}(1) \\
\text { Positive } \\
\text { significance, } \\
\text { unweighted }\end{array}$ & $\begin{array}{c}(2) \\
\text { Positive } \\
\text { significance, } \\
\text { unweighted }\end{array}$ & $\begin{array}{c}(3) \\
\text { Positive } \\
\text { significance, } \\
\text { unweighted }\end{array}$ & $\begin{array}{c}(4) \\
\text { Positive } \\
\text { significance, } \\
\text { unweighted }\end{array}$ & $\begin{array}{c}(5) \\
\text { Positive } \\
\text { significance, } \\
\text { weighted }\end{array}$ & $\begin{array}{c}(6) \\
\text { Effect } \\
\text { size, } \\
\text { unweighted }\end{array}$ & $\begin{array}{c}(7) \\
\text { Effect } \\
\text { size, } \\
\text { weighted }\end{array}$ \\
\hline \multicolumn{8}{|l|}{ Program type } \\
\hline Training & Ref. & & & Ref. & Ref. & Ref. & Ref. \\
\hline Finance & $\begin{array}{r}-0.048 \\
(0.123)\end{array}$ & & & $\begin{array}{l}-0.227 \\
(0.147)\end{array}$ & $\begin{array}{r}-0.294 * * \\
(0.136)\end{array}$ & $\begin{array}{r}-0.217^{* *} \\
(0.102)\end{array}$ & $\begin{array}{l}-0.245^{*} \\
(0.130)\end{array}$ \\
\hline $\begin{array}{l}\text { Business development } \\
\text { services }\end{array}$ & $\begin{array}{r}0.225 \\
(0.156)\end{array}$ & & & $\begin{array}{r}-0.012 \\
(0.186)\end{array}$ & $\begin{array}{l}-0.007 \\
(0.197)\end{array}$ & $\begin{array}{l}-0.0723 \\
(0.123)\end{array}$ & $\begin{array}{r}-0.082 \\
(0.134)\end{array}$ \\
\hline $\begin{array}{l}\text { Private sector incentives and } \\
\text { business environment }\end{array}$ & $\begin{array}{r}0.332 * * \\
(0.138)\end{array}$ & & & $\begin{array}{r}0.154 \\
(0.205)\end{array}$ & $\begin{array}{r}0.060 \\
(0.225)\end{array}$ & $\begin{array}{r}-0.105 \\
(0.112)\end{array}$ & $\begin{array}{r}-0.106 \\
(0.144)\end{array}$ \\
\hline \multicolumn{7}{|l|}{ Firm size } & Ref. \\
\hline Small enterprises & & $\begin{array}{r}0.482 * * * \\
(0.104)\end{array}$ & & $\begin{array}{r}0.410 * * \\
(0.173)\end{array}$ & $\begin{array}{r}0.371^{* *} \\
(0.186)\end{array}$ & $\begin{array}{r}0.126 \\
(0.136)\end{array}$ & $\begin{array}{l}0.0457 \\
(0.154)\end{array}$ \\
\hline Medium-sized enterprises & & $\begin{array}{r}0.176 \\
(0.170)\end{array}$ & & $\begin{array}{r}0.107 \\
(0.250)\end{array}$ & $\begin{array}{r}0.0712 \\
(0.243)\end{array}$ & $\begin{array}{r}-0.102 \\
(0.141)\end{array}$ & $\begin{array}{r}-0.182 \\
(0.174)\end{array}$ \\
\hline Empl. creat. primary objective & & $\begin{array}{r}0.0856 \\
(0.133)\end{array}$ & & $\begin{array}{r}0.050 \\
(0.137)\end{array}$ & $\begin{array}{r}0.024 \\
(0.152)\end{array}$ & $\begin{array}{r}0.022 \\
(0.083)\end{array}$ & $\begin{array}{r}0.040 \\
(0.098)\end{array}$ \\
\hline Joint intervention & & $\begin{array}{l}0.0001 \\
(0.128)\end{array}$ & & $\begin{array}{r}-0.110 \\
(0.170)\end{array}$ & $\begin{array}{r}-0.209 \\
(0.148)\end{array}$ & $\begin{array}{r}0.0004 \\
(0.0739)\end{array}$ & $\begin{array}{r}-0.032 \\
(0.0871)\end{array}$ \\
\hline Intervention targets women & & $\begin{array}{l}-0.244 * \\
(0.128)\end{array}$ & & $\begin{array}{r}-0.216 \\
(0.140)\end{array}$ & $\begin{array}{l}-0.272 * \\
(0.143)\end{array}$ & $\begin{array}{r}-0.027 \\
(0.081)\end{array}$ & $\begin{array}{r}-0.072 \\
(0.101)\end{array}$ \\
\hline Evaluation based on an RCT & & & & $\begin{array}{l}-0.334 * \\
(0.176)\end{array}$ & $\begin{array}{r}-0.365^{* *} \\
(0.172)\end{array}$ & $\begin{array}{r}-0.107 \\
(0.140)\end{array}$ & $\begin{array}{r}-0.087 \\
(0.156)\end{array}$ \\
\hline Outcome is business creation & & & $\begin{array}{r}-0.135 \\
(0.097)\end{array}$ & $\begin{array}{r}0.130 \\
(0.132)\end{array}$ & $\begin{array}{l}0.240 * \\
(0.138)\end{array}$ & $\begin{array}{r}0.014 \\
(0.051)\end{array}$ & $\begin{array}{r}0.011 \\
(0.055)\end{array}$ \\
\hline $\begin{array}{l}\text { Country income category } \\
\text { LIC }\end{array}$ & & & & Ref. & Ref. & Ref. & Ref. \\
\hline LMIC & & & & $\begin{array}{r}-0.053 \\
(0.214)\end{array}$ & $\begin{array}{r}-0.035 \\
(0.235)\end{array}$ & $\begin{array}{r}-0.102 \\
(0.114)\end{array}$ & $\begin{array}{r}-0.111 \\
(0.125)\end{array}$ \\
\hline UMIC & & & & $\begin{array}{r}-0.186 \\
(0.233)\end{array}$ & $\begin{array}{r}-0.146 \\
(0.247)\end{array}$ & $\begin{array}{r}-0.106 \\
(0.150)\end{array}$ & $\begin{array}{r}-0.072 \\
(0.180)\end{array}$ \\
\hline Effect size measure is SMD & & & & & & $\begin{array}{r}0.138 \\
(0.098)\end{array}$ & $\begin{array}{r}0.154 \\
(0.121)\end{array}$ \\
\hline Square root of sample size & & & & $\begin{array}{l}-0.0001 \\
(0.0002)\end{array}$ & $\begin{array}{r}-0.0001 \\
(0.0002)\end{array}$ & $\begin{array}{r}-0.0002 \\
(0.0001)\end{array}$ & $\begin{array}{l}-0.0002 \\
(0.0001)\end{array}$ \\
\hline Intercept & & & & & & $\begin{array}{r}0.317 \\
(0.215) \\
\end{array}$ & $\begin{array}{r}0.340 \\
(0.243) \\
\end{array}$ \\
\hline Observations & 116 & 116 & 116 & 116 & 116 & 115 & 115 \\
\hline Pseudo R2 & 0.051 & 0.156 & 0.013 & 0.210 & 0.205 & 0.220 & 0.197 \\
\hline
\end{tabular}

Notes: Robust standard errors clustered at the level of studies in parentheses. ${ }^{* * *} \mathrm{p}<0.01,{ }^{* *} \mathrm{p}<0.05,{ }^{*} \mathrm{p}<0.1$.

Source: Own data. 
Figure 1: Simplified results chain linking interventions and employment outcomes

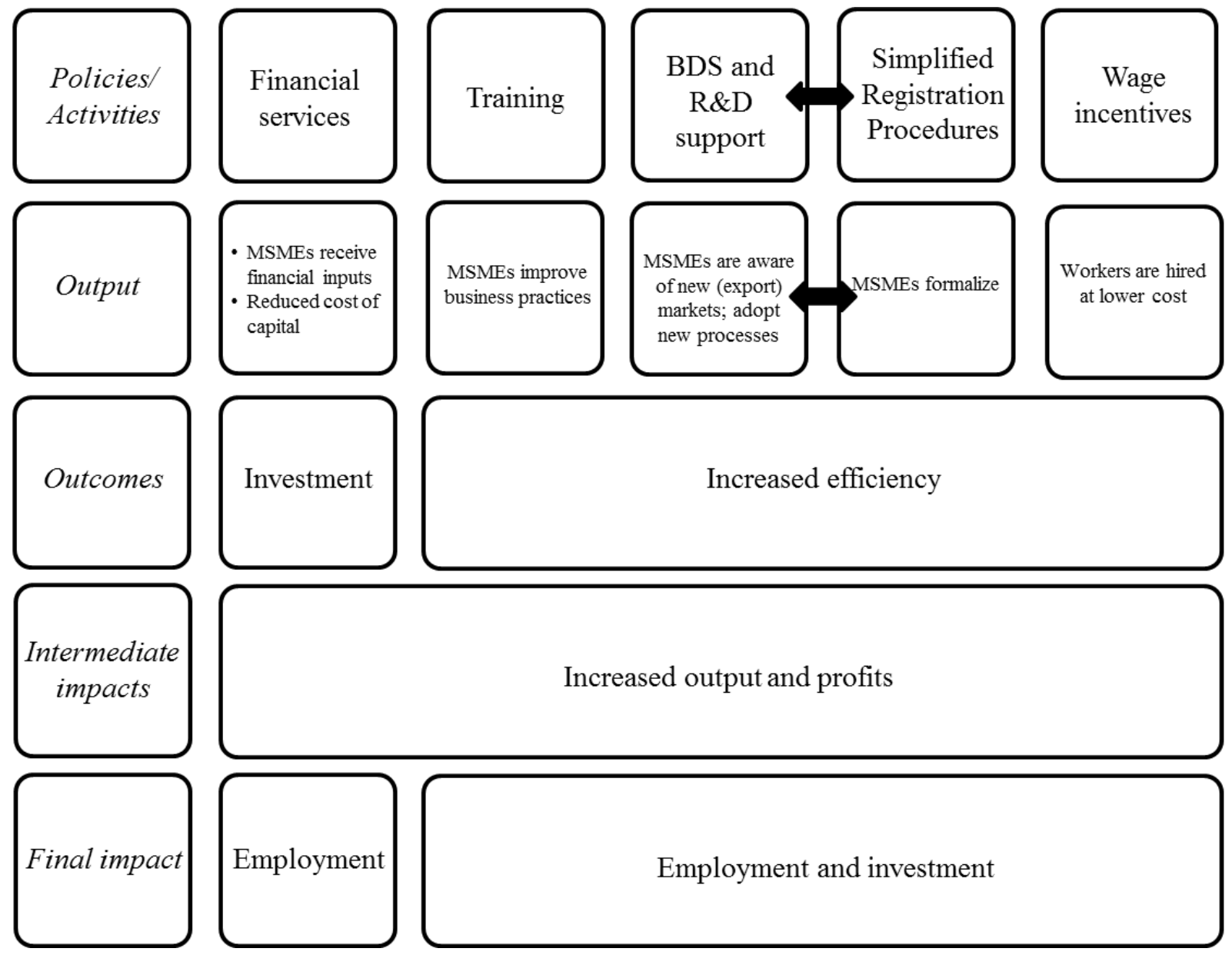

Source: Own representation.

Figure 2: Selection of studies

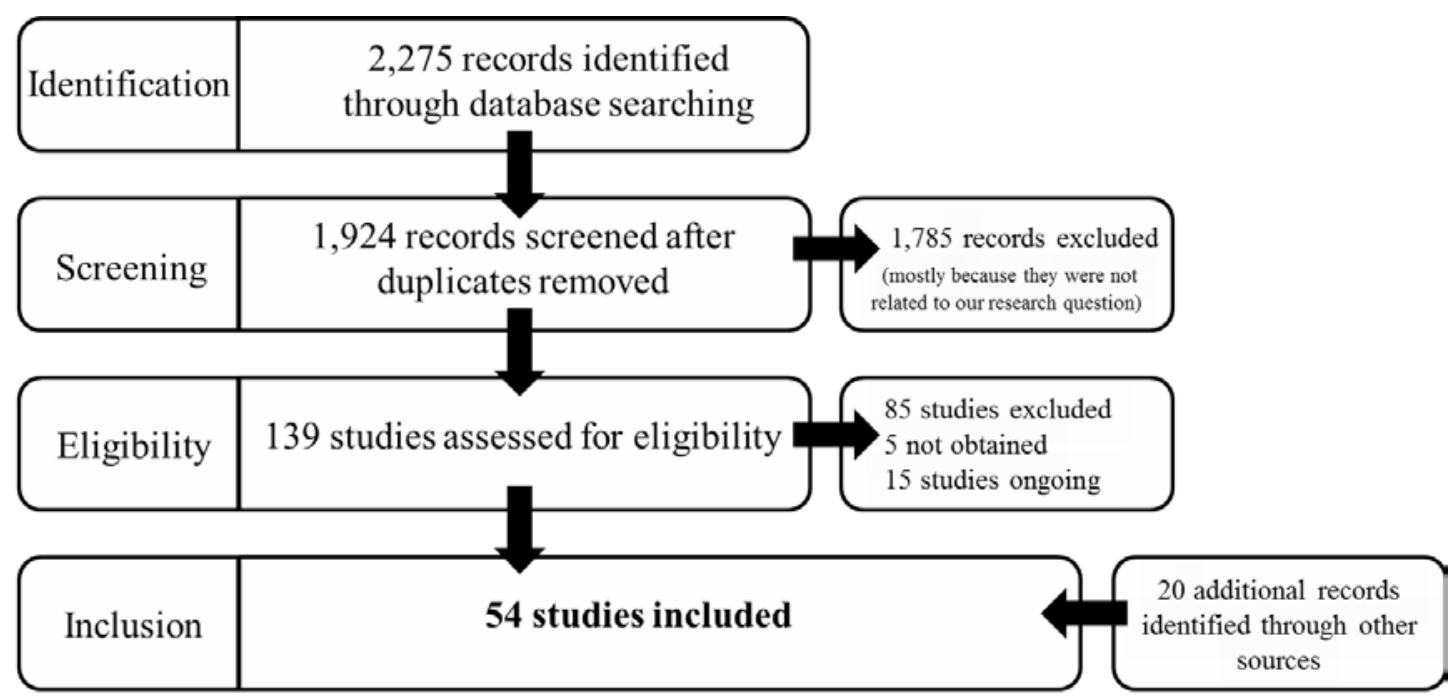

Source: Own representation. 